\title{
EBV-induced gene 3 augments IL-23R $\alpha$ protein expression through a chaperone calnexin
}

\author{
Izuru Mizoguchi, ${ }^{1}$ Mio Ohashi, ${ }^{1}$ Hideaki Hasegawa, ${ }^{1}$ Yukino Chiba, ${ }^{1}$ Naoko Orii, ${ }^{1}$ Shinya Inoue, ${ }^{1}$ Chiaki Kawana, ${ }^{1}$ Mingli Xu, ${ }^{1}$ \\ Katsuko Sudo, ${ }^{2}$ Koji Fujita, ${ }^{3}$ Masahiko Kuroda, ${ }^{3}$ Shin-ichi Hashimoto, ${ }^{4}$ Kouji Matsushima, ${ }^{5}$ and Takayuki Yoshimoto ${ }^{1}$ \\ 'Department of Immunoregulation, Institute of Medical Science, ${ }^{2}$ Animal Research Center, and ${ }^{3}$ Department of Molecular Pathology, Tokyo Medical University, Tokyo, Japan. ${ }^{4}$ Department of Laboratory \\ Medicine, Faculty of Medicine, Institute of Medical, Pharmaceutical and Health Sciences, Kanazawa University, Ishikawa, Japan. ${ }^{5}$ Department of Molecular Preventive Medicine, School of Medicine, \\ University of Tokyo, Tokyo, Japan.
}

\begin{abstract}
Epstein-Barr virus-induced gene 3 (EBI3) is a subunit common to IL-27, IL-35, and IL-39. Here, we explore an intracellular role of EBI3 that is independent of its function in cytokines. EBI3-deficient naive $\mathrm{CD}^{+} \mathrm{T}$ cells had reduced IFN- $\gamma$ production and failed to induce $\mathrm{T}$ cell-dependent colitis in mice. Similarly reduced IFN- $\gamma$ production was observed in vitro in EBI3-deficient $\mathrm{CD}^{+} \mathrm{T}$ cells differentiated under pathogenic Th17 polarizing conditions with IL-23. This is because the induction of expression of one of the IL-23 receptor (IL-23R) subunits, IL-23R $\alpha$, but not another IL-23R subunit, IL-12Rß1, was selectively decreased at the protein level, but not the mRNA level. EBI3 augmented IL-23R $\alpha$ expression via binding to the chaperone molecule calnexin and to IL-23R $\alpha$ in a peptide-dependent manner, but not a glycan-dependent manner. Indeed, EBI3 failed to augment IL-23R $\alpha$ expression in the absence of endogenous calnexin. Moreover, EBI3 poorly augmented the expression of C149R, an IL-23R $\alpha$ variant that protects against the development of human colitis, because binding of EBI3 to the variant was reduced. Taken together with the result that EBI3 expression is inducible in T cells, the present results suggest that EBI3 plays a critical role in augmenting IL-23R $\alpha$ protein expression via calnexin under inflammatory conditions.
\end{abstract}

\section{Introduction}

Cytokines of the IL-12 family play critical roles in regulating the differentiation of Th cells and their effector functions (1). These cytokines are composed of 2 distinct subunits forming a heterodimer, with each subunit occurring in others as well. Among the subunits, the Epstein-Barr virus-induced gene 3 (EBI3) molecule was initially identified as being induced by infection with EBV in B cells (2). This secreted glycoprotein is a member of the hematopoietin receptor family related to the 440 subunit of IL-12. EBI3 was later demonstrated to associate with p28, p35, and p19 in turn, forming the heterodimers of IL-27 (3), IL-35 (4), and IL-39 (5), respectively. IL-27 has multiple functions, with both proinflammatory and antiinflammatory properties, including promotion of early Th1 differentiation, generation of IL-10-producing regulatory T cells, and suppression of Th2 and Th17 differentiation $(6,7)$. IL-35 is an antiinflammatory cytokine that is produced by Foxp ${ }^{+}$ Tregs $(4,8)$ and regulatory B (Breg) cells (9). Its functions include inhibition of cell proliferation and suppression of the development of autoimmune diseases. Very recently, IL-39 was reported to be secreted by activated B cells and to induce differentiation and expansion of neutrophils in lupus-prone mice $(5,9)$.

Inflammatory bowel diseases (IBDs), including Crohn's disease and ulcerative colitis, are chronic inflammatory disorders

Conflict of interest: The authors have declared that no conflict of interest exists. Copyright: () 2020, American Society for Clinical Investigation.

Submitted: June 7, 2018; Accepted: August 5, 2020; Published: October 12, 2020.

Reference information: J Clin Invest. 2020;130(11):6124-6140.

https://doi.org/10.1172/JCI122732. of the gastrointestinal tract caused by an inappropriate immune response to intestinal microflora $(10,11)$. In several experimental models of T cell-dependent and innate colitis, IL-23 was found to play an essential role in inducing intestinal inflammation (12-16). Initial findings indicated that IL-23 supports the expansion and maintenance of Th17 cells and is critically important for the development of pathogenic Th17 cells, without inducing secretion of IL-10 (17). However, because Th17 cells can acquire functional characteristics of Th1 cells, they were subsequently demonstrated to have a great degree of context-dependent plasticity, specifically the ability to extinguish IL-17 expression and turn on IFN- $\gamma$ production to become IFN- $\gamma^{+}$ex-Th17 cells (18-22). IL-23 was identified as a key driver of Th17 cell plasticity, which is critically important for the development of inflammation and autoimmunity as well as protection against microbes (22). Of note, several single-nucleotide polymorphisms in the IL-23 receptor $\alpha$ (IL-23R $\alpha$ ) gene locus have been reported to be associated with susceptibility to IBD in genome-wide association studies of large cohorts of IBD patients and healthy controls, strongly indicating that IL-23 is important for IBD pathogenesis $(23,24)$.

After finding that EBI3 expression is induced in naive CD4 ${ }^{+} \mathrm{T}$ cells by stimulation with plate-bound anti-CD3 and anti-CD28, we sought to identify a role for $\mathrm{EBI} 3$ in $\mathrm{CD}^{+} \mathrm{T}$ cells and to clarify its mode of function by using a $\mathrm{T}$ cell-dependent mouse colitis model. In this model, colitis is induced by adoptive transfer of naive $\mathrm{CD} 4^{+}$ $\mathrm{T}$ cells into immunodeficient mice. EBI3-deficient naive $\mathrm{CD} 4^{+} \mathrm{T}$ cells failed to induce colitis due to reduced expression of IL-23R $\alpha$ at the protein level, but not at the mRNA level. EBI3 was thus revealed to have the ability to augment IL-23R $\alpha$ expression at the protein lev- 
el via binding to the chaperone molecule calnexin and to IL-23R $\alpha$. Calnexin is a well-characterized lectin chaperone involved in the proper folding of newly synthesized glycoproteins in the lumen of the ER (25-27). Recently, the IL-23R $\alpha$ variants G149R, V362I, and $\mathrm{R} 381 \mathrm{Q}$, which are protective against the development of IBD in humans, were demonstrated to have loss of function due to impaired protein stability and resultant decreased signaling by IL-23 (28). Of note, EBI3 had minimal impact on augmenting the expression of its variant G149R, which is located in the extracellular region of IL-23R $\alpha$, because binding of EBI3 to the variant was substantially reduced. This report is the first, to our knowledge, to demonstrate a role for EBI3 as an intracellular molecule acting independently of the cytokines for which it is a component.

\section{Results}

Impaired induction of colitis by transfer with EBI3-deficient naive $\mathrm{CD}^{+} \mathrm{T}$ cells into immunodeficient mice. EBI3 was previously reported to be constitutively expressed in Foxp $3^{+} \mathrm{CD} 4^{+} \mathrm{CD} 25^{+}$Tregs and to play a critical role in their suppressive activity (4). We initially noticed that EBI3 mRNA expression was minimal in naive $\mathrm{CD}^{+}$ $\mathrm{T}$ cells, but expression was rapidly induced after stimulation with plate-bound anti-CD3 and anti-CD28, as in the case of Tregs (Figure 1A). In contrast, p28 and p35 mRNA expression were undetectable in naive $\mathrm{CD} 4^{+} \mathrm{T}$ cells and poorly induced by stimulation. Similar results were obtained at the protein level in Western blot analysis (Figure 1B and Supplemental Figure 1; supplemental material available online with this article; https://doi.org/10.1172/ JCI122732DS1). These results suggest that EBI3 may function independently of IL-27 and IL-35.

To investigate the role of EBI 3 in naive $\mathrm{CD}^{+} \mathrm{T}$ cells, we used a $\mathrm{T}$ cell-dependent colitis model, in which colitis is induced by transfer of naive $\mathrm{CD} 4{ }^{+} \mathrm{CD} 25^{-} \mathrm{CD} 62 \mathrm{~L}^{+} \mathrm{T}$ cells into RAG2-deficient mice. First, 3 weeks after the transfer, the colons were removed, $\mathrm{CD}^{+} \mathrm{T}$ cells were purified from mononuclear cells of the intestinal lamina propria, and the resultant cell lysates were subjected to Western blotting. Consistent with the in vitro result, EBI3 expression at the protein level was increased during the course of colitis (Figure 1C). RAG2-deficient mice that received WT naive $\mathrm{CD} 4^{+} \mathrm{T}$ cells showed decreased body weight (Figure 1D), shortened colon length (Figure 1, E and F), and colonic inflammatory changes (Figure $1, \mathrm{G}$ and $\mathrm{H}$ ). In marked contrast, mice that received EBI3-deficient naive $\mathrm{CD}^{+} \mathrm{T}$ cells showed markedly reduced body weight loss, diminished macroscopic evidence of colitis, as defined by colon shortening, and a dramatic decrease in histological evidence of colonic inflammatory changes. These results suggest that EBI3 in naive $\mathrm{CD} 4^{+} \mathrm{T}$ cells plays a pathological role in the colitis model.

Decreased IFN- $\gamma$ production in intestinal lamina propria of immunodeficient mice transferred with EBI3-deficient naive $C D 4^{+} \mathrm{T}$ cells. We then examined the molecular mechanism whereby EBI3 promotes the development of colitis. We first confirmed the initial transfer rate and the level of Tregs between RAG2-deficient mice that received WT naive $\mathrm{CD} 4^{+} \mathrm{T}$ cells or $\mathrm{EBI} 3$-deficient naive $\mathrm{CD} 4^{+}$ T cells 3 weeks after the transfer, when the body weight change just started to diverge. Percentages of $\mathrm{CD} 4^{+} \mathrm{T}$ cells in the mononuclear cells of intestinal lamina propria between these mice were comparable, indicating the initial transfer appeared to be performed equally (Figure 2A). Moreover, percentages of Foxp $3^{+} \mathrm{CD} 4^{+} \mathrm{CD} 25^{+}$
Tregs were almost negligible in both mice, as expected (Figure 2B). Because IL-23-mediated intestinal IFN- $\gamma$ production is necessary for the development of colitis (18-22), the frequency of cytokine-producing mononuclear cells of the intestinal lamina propria was then determined by intracellular staining. Notably, the frequency of IFN- $\gamma^{+}$IL- $-17^{-} \mathrm{CD} 4^{+} \mathrm{T}$ cells was significantly decreased in the RAG2-deficient mice that received EBI3-deficient naive $\mathrm{CD} 4^{+}$ T cells compared with the RAG2-deficient mice that received WT naive $\mathrm{CD} 4^{+} \mathrm{T}$ cells even at this early time point (Figure $2, \mathrm{C}$ and $\mathrm{D}$ ). No difference was observed in the frequency of IFN- $\gamma^{+} \mathrm{IL}-17^{+} \mathrm{CD} 4^{+}$ $\mathrm{T}$ cells and IFN- $\gamma^{-} \mathrm{IL}-17^{+} \mathrm{CD} 4^{+} \mathrm{T}$ cells. Next, similar analyses were performed 8 weeks after the transfer. The frequency of IFN- $\gamma^{+}$ IL- $17^{-} \mathrm{CD} 4^{+} \mathrm{T}$ cells was much more decreased in the RAG2-deficient mice that received EBI3-deficient naive $\mathrm{CD} 4^{+} \mathrm{T}$ cells than the RAG2-deficient mice that received WT naive $\mathrm{CD}^{+} \mathrm{T}$ cells (Figure 2, E and F). Similarly reduced IFN- $\gamma$ production was observed when the mononuclear cells were restimulated with soluble anti-CD3 and culture supernatants were assayed by ELISA (Figure 2G). Moreover, the production of GM-CSF and TNF- $\alpha$ was also diminished, although almost no significant difference was detected in the production of IL-6, IL-17, and IL-22 (Figure $2 \mathrm{G})$. Thus, IFN- $\gamma$ production was most consistently reduced in the intestinal lamina propria of RAG2-deficient mice transferred with EBI3-deficient naive $\mathrm{CD} 4^{+} \mathrm{T}$ cells, which could largely explain the impaired induction of colitis (18-21).

Decreased IFN- $\gamma$ production in EBI3-deficient $C D 4^{+} T$ cells differentiated under pathogenic Th17 polarizing conditions with IL-23 in vitro. To further examine the role of EBI3 in cytokine production, naive $\mathrm{CD}^{+}{ }^{+} \mathrm{T}$ cells from WT mice or EBI3-deficient mice were stimulated in vitro with soluble anti-CD3 in the presence of irradiated WT spleen cells depleted of T and NK cells under Th1 polarizing conditions (Supplemental Figure 2A), nonpathogenic Th17 polarizing conditions with TGF- $\beta 1+$ hyper-IL-6 (Supplemental Figure $2 \mathrm{~B}$ ), and pathogenic Th17 polarizing conditions with IL-1 $\beta+$ hyper-IL-6+IL-23 for 4 days (Supplemental Figure 2C). Then resultant cells were restimulated with PMA and ionomycin, followed by intracellular staining. Consistent with the in vivo results (Figure 2), the frequency of IFN- $\gamma^{+} \mathrm{IL}-17^{-} \mathrm{CD} 4^{+} \mathrm{T}$ cells differentiated under pathogenic Th17 polarizing conditions was significantly decreased in EBI3-deficient naive $\mathrm{CD} 4^{+} \mathrm{T}$ cells compared with WT naive $\mathrm{CD} 4^{+}$ T cells (Supplemental Figure 2C). Although a similar tendency was seen in the frequency of IFN $-\gamma^{+} \mathrm{IL}-17^{+} \mathrm{CD} 4^{+} \mathrm{T}$ cells, the frequency of IFN- $\gamma^{-} \mathrm{IL}-17^{+} \mathrm{CD} 4^{+} \mathrm{T}$ cells did not differ between EBI3-deficient and WT naive $\mathrm{CD} 4^{+} \mathrm{T}$ cells, as previously reported (29). In contrast, no significant difference was observed in the frequency of these cells between EBI3-deficient and WT naive $\mathrm{CD}^{+}{ }^{+} \mathrm{T}$ cells differentiated under the Th1 polarizing and nonpathogenic Th17 polarizing conditions (Supplemental Figure 2, A and B). These results suggest that IFN- $\gamma$ production was substantially reduced in EBI3-deficient naive $\mathrm{CD} 4^{+} \mathrm{T}$ cells differentiated under pathogenic Th17 polarizing conditions with IL-23 in vitro as well.

Soluble EBI3 secreted from $W T C D 4^{+} T$ cells failed to restore reduced IFN- $\gamma$ production in EBI3-deficient $C D 4^{+} T$ cells. If EBI3 could function as a cytokine by forming a heterodimer with another molecule, a homodimer, or a monomer, these molecules would have to be secreted outside of the cells. To determine whether EBI3 functions as a soluble factor, we next used green mice, which 
A

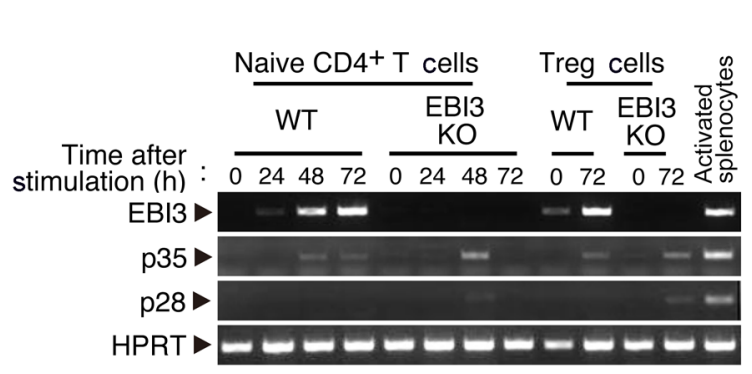

D

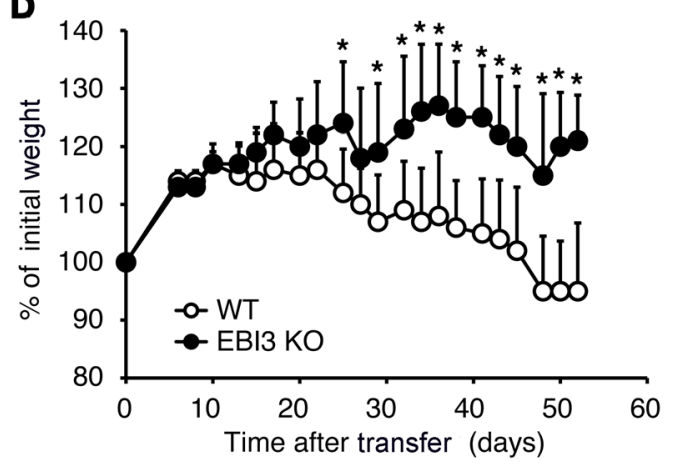

B

Time after stimulation: (days)
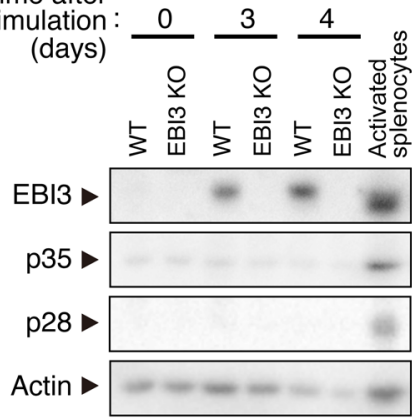

E

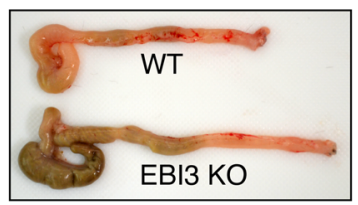

G

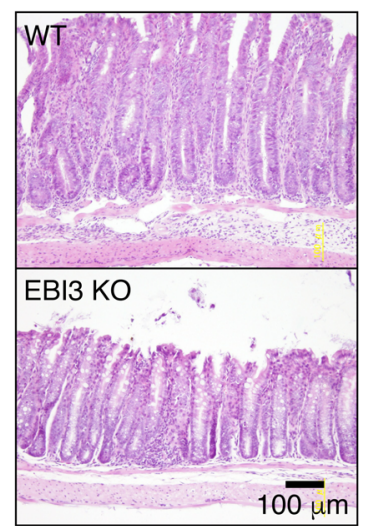

C

Time after

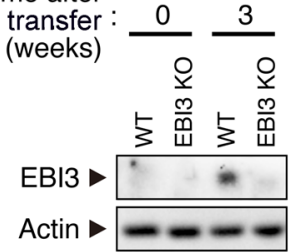

F

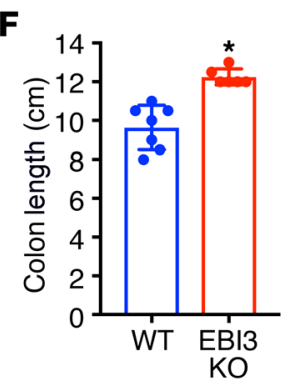

H

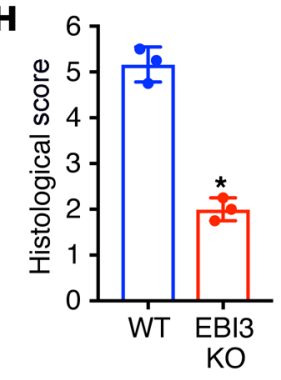

Figure 1. Impaired induction of colitis by transfer with EBI3-deficient naive CD4+ $\mathbf{T}$ cells into immunodeficient mice. (A and B) Naive $C D 44^{+} \mathrm{CD} 25^{-} \mathrm{CD} 62 \mathrm{~L}^{+}$ T cells from WT mice were stimulated with plate-bound anti-CD3 and soluble anti-CD28. RNA was prepared at the indicated times and subjected to semiquantitative RT-PCR analysis (A). In addition, CD4+CD25+ Tregs and spleen cells were similarly activated and analyzed. Cell lysates were also prepared and subjected to Western blotting (B). (C-H) Naive CD4+ ${ }^{+}$cells were isolated from spleens of WT mice or EBI3-deficient mice and transferred into RAC2deficient mice. Three weeks after transfer, colons were removed, $C D 4^{+} T$ cells were purified from mononuclear cells of the intestinal lamina propria by AutoMACS Pro, and resultant cell lysates were subjected to Western blotting (C). Mice were monitored for weight loss (D), and 8 weeks after the transfer, colons were removed, and their lengths were measured from rectum to cecum (E and $\mathbf{F}$ ). Representative photographs of colons $(\mathbf{E})$ and $H \& E$ staining of colons (G) are shown. Histological scoring of colitis severity was measured $(\mathbf{H})$. Data are shown as mean \pm SD $(n=6-7, \mathbf{D}-\mathbf{H} ; n=3, \mathbf{G}$ and $\mathbf{H})$ and are representative of $2(\mathbf{A}-\mathbf{C})$ or $3(\mathbf{D}-\mathbf{H})$ independent experiments. $P$ values were determined using unpaired, 2-tailed Student's $t$ test $(\mathbf{D}, \mathbf{F}$, and $\mathbf{H})$. ${ }^{*} P<0.05$.

are transgenic mice ubiquitously and constitutively expressing enhanced GFP cDNA (30). Naive CD4 ${ }^{+} \mathrm{T}$ cells from green mice, EBI3-deficient mice, or an equal mixture of these cells were stimulated with soluble anti-CD3 in the presence of irradiated WT spleen cells depleted of $\mathrm{T}$ and NK cells under pathogenic Th17 polarizing conditions with IL-23 for 4 days. Then intracellular cytokine staining was performed by gating $\mathrm{GFP}^{+} \mathrm{CD} 4^{+} \mathrm{T}$ cells and $\mathrm{GFP}^{-} \mathrm{CD}^{+}{ }^{+} \mathrm{T}$ cells, which corresponded to $\mathrm{EBI}^{++\mid}$cells and $\mathrm{EBI}^{--}$ cells, respectively. In the individual culture system, the frequency of IFN- $\gamma^{+} \mathrm{IL}-17^{-} \mathrm{CD} 4^{+} \mathrm{T}$ cells in GFP-EBI3 $3^{--}$cells was significantly reduced compared with that in $\mathrm{GFP}^{+} \mathrm{EBI}^{+/+}$cells (Figure $3 \mathrm{~A}$ ), which is consistent with the results shown in Supplemental Figure 2C. However, in the coculture system with the presence of $\mathrm{GFP}^{+} \mathrm{EBI}^{+++} \mathrm{CD}^{+} \mathrm{T}$ cells, the frequency of IFN- $\gamma^{+} \mathrm{IL}-17^{-} \mathrm{CD} 4^{+}$ $\mathrm{T}$ cells in $\mathrm{GFP}^{-} \mathrm{EBI}^{--} \mathrm{CD}^{+} \mathrm{T}$ cells was notably not increased as in $\mathrm{GFP}^{+} \mathrm{EBI}^{++} \mathrm{CD}^{+} \mathrm{T}$ cells (Figure 3B). Thus, even in the coculture system, the reduced frequency of IFN- $\gamma^{+} \mathrm{IL}-17^{-} \mathrm{CD} 4^{+} \mathrm{T}$ cells in $\mathrm{EBI}^{--} \mathrm{CD}^{+} \mathrm{T}$ cells could not be rescued by the presence of $\mathrm{EBI}^{++} \mathrm{CD}^{+} \mathrm{T}$ cells through a soluble factor. It was recently reported that EBI3 is secreted by activated $\mathrm{CD}_{4}{ }^{+} \mathrm{T}$ cells and promotes $\mathrm{T}$ cell division and differentiation (31). Consistent with that report, soluble EBI3 was detected, but was less than $100 \mathrm{pg} / \mathrm{mL}$ in the culture supernatant of activated $\mathrm{CD} 4^{+} \mathrm{T}$ cells by ELISA (Figure 3C). However, recombinant $\mathrm{EBI} 3 \mathrm{up}$ to $10 \mathrm{ng} / \mathrm{mL}$ failed to restore the decreased frequency of IFN- $\gamma^{+} I L-17^{-} \mathrm{CD} 4^{+} \mathrm{T}$ cells in EBI3-deficient $\mathrm{CD} 4^{+} \mathrm{T}$ cells (Figure 3D). Thus, $\mathrm{EBI} 3$ in $\mathrm{CD} 4^{+} \mathrm{T}$ cells plays its role as an intracellular molecule rather than a soluble factor.

Decreased IFN- $\gamma$ production in EBI3-deficient $C D 4^{+} T$ cells is attributed to reduced IL-23 signaling. To elucidate the molecular mechanisms whereby EBI3 regulates IFN- $\gamma$ production 
A

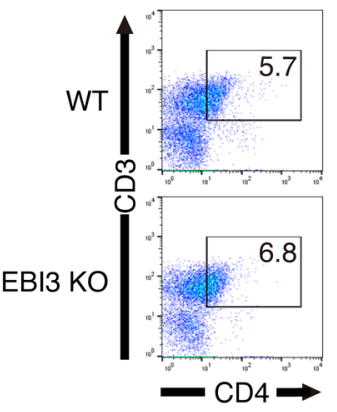

3 weeks

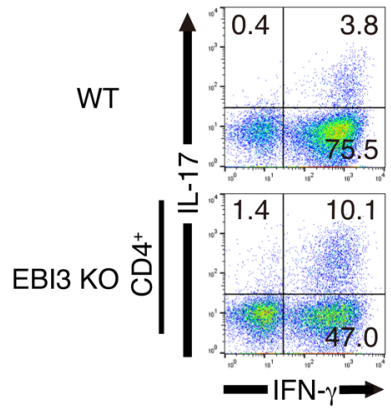

E 8 weeks

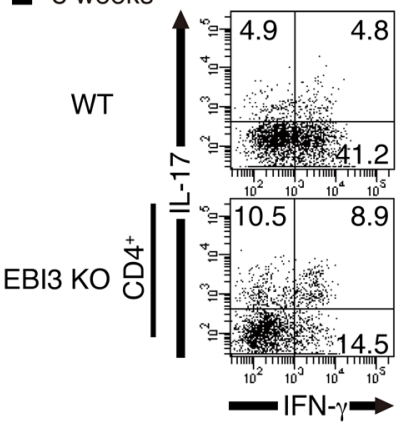

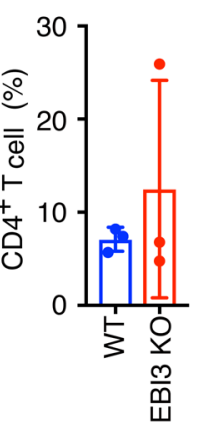

B

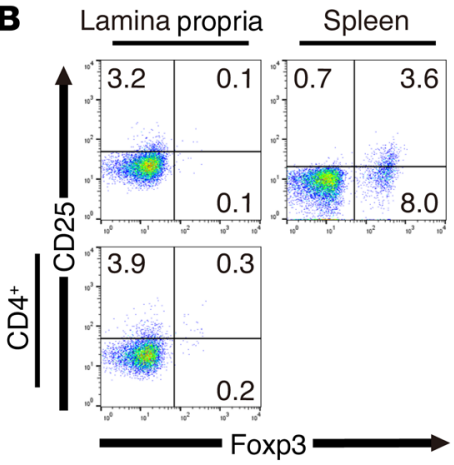

D $\quad \mathrm{IFN}-\gamma^{+} \mathrm{IL}-17^{-}$

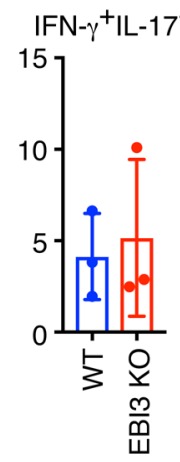

$\mathrm{IFN}-\gamma^{-} \mathrm{IL}-17^{+}$
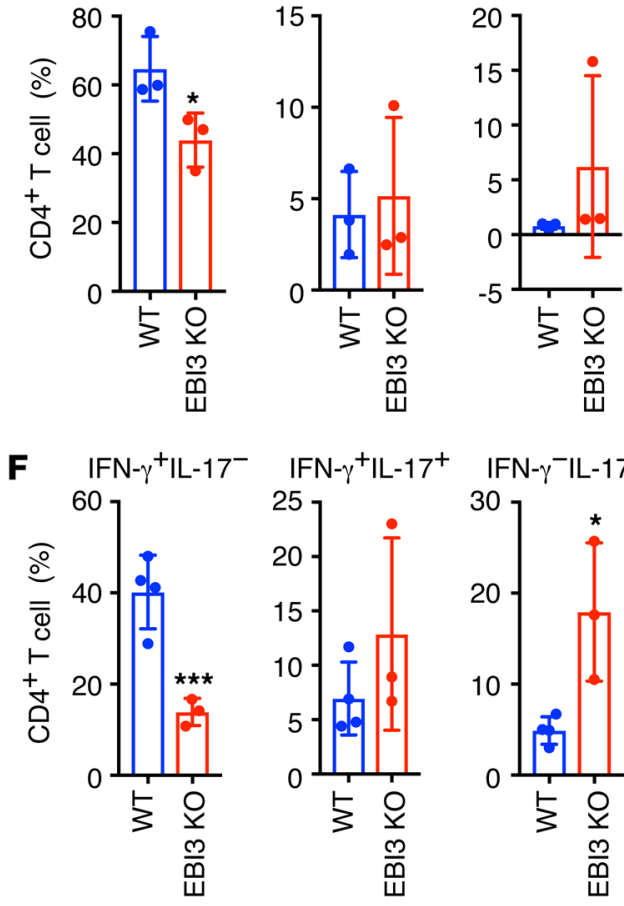

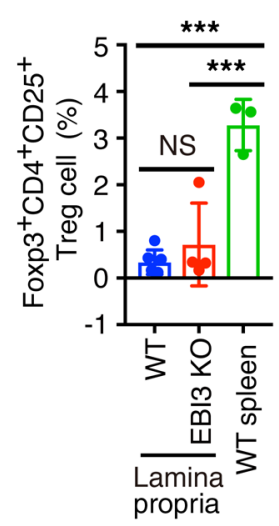

propria
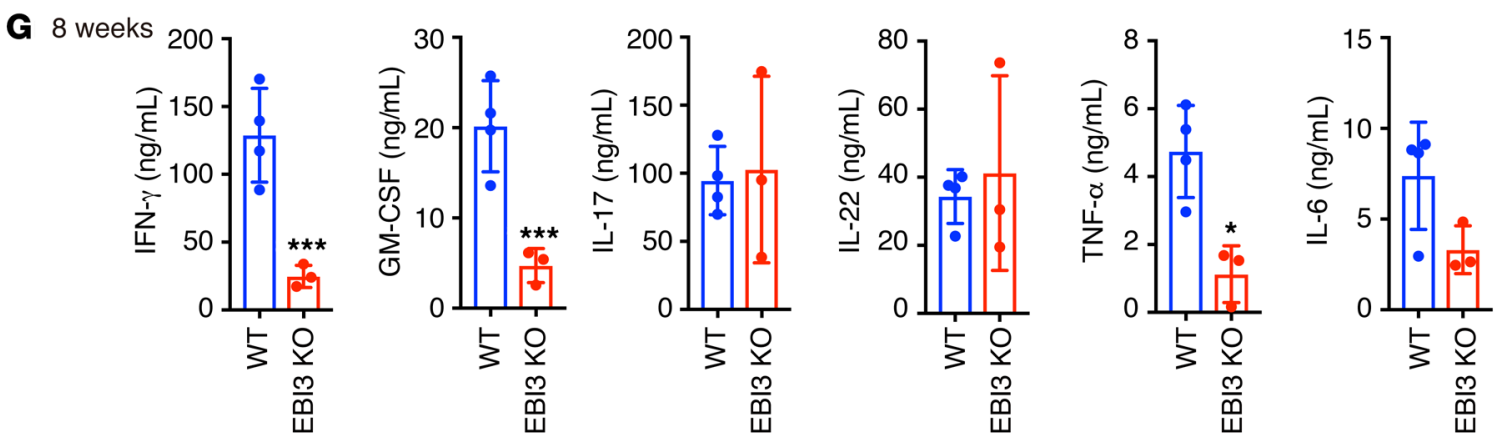

Figure 2. Decreased IFN- $\gamma$ production in intestinal lamina propria lymphocytes of immunodeficient mice transferred with EBI3-deficient naive CD4 ${ }^{+}$ T cells. (A-C) Intestinal lamina propria mononuclear cells were isolated from colons of RAG2-deficient mice and transferred with WT naive CD4 ${ }^{+}$T cells or EBI3-deficient naive CD4 ${ }^{+}$T cells 3 weeks after transfer. Cell-surface staining of intestinal lamina propria mononuclear cells and intracellular cytokine staining after restimulation with PMA and ionomycin were performed. Spleen cells from WT mice were used as positive controls for staining Foxp $3^{+}$ $\mathrm{CD} 4{ }^{+} \mathrm{CD} 25^{+}$Tregs. Representative dot plots of $\mathrm{CD} 4^{+} \mathrm{T}$ cells and Foxp3 ${ }^{+} \mathrm{CD} 4^{+} \mathrm{CD} 25^{+}$Tregs are shown, and resultant percentages were calculated (A and $\left.\mathbf{B}\right)$. Representative dot plots of IFN- $\gamma$ and IL-17 in CD4+ $T$ cells are shown (C), and the frequencies of respective CD4 ${ }^{+} T$ cells were calculated (D). Intestinal lamina propria mononuclear cells were similarly analyzed 8 weeks later. Representative dot plots of IFN- $\gamma$ and IL-17 in CD4+ ${ }^{+}$cells are shown (E), and the frequencies of respective CD4 ${ }^{+} T$ cells were calculated (F). (C) Lamina propria mononuclear cells were also restimulated with soluble anti-CD3 for 48 hours, and the culture supernatant was assayed for cytokine production by ELISA. Data are shown as mean \pm SD $(n=3-6)$ and are representative of 2 independent experiments. $P$ values were determined using unpaired, 2 -tailed Student's $t$ test $(\mathbf{A}, \mathbf{D}, \mathbf{F}$, and $\mathbf{G})$ or 1-way ANOVA $(\mathbf{B}) .{ }^{*} P<0.05 ;{ }^{* * *} P<0.001$. 
A Individual cultures
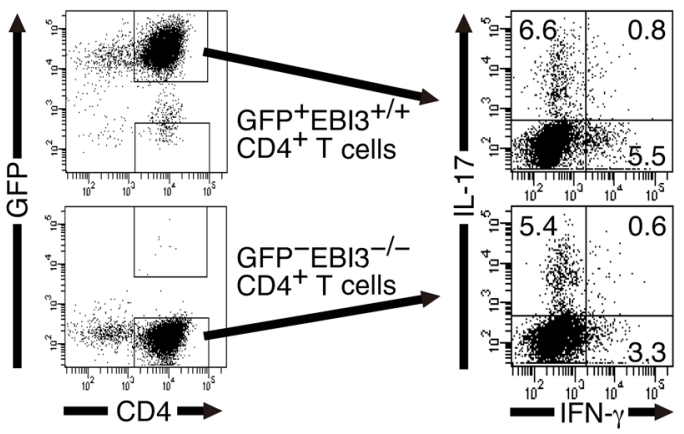

$\mathrm{IFN}-\gamma^{+} \mathrm{IL}-17^{-} \quad \mathrm{IFN}-\gamma^{+} \mathrm{IL}-17^{+}$
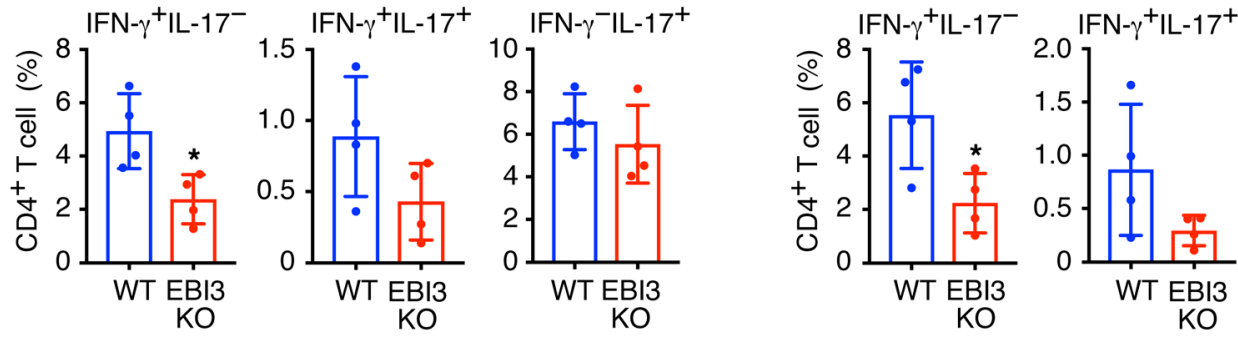

B Co-culture
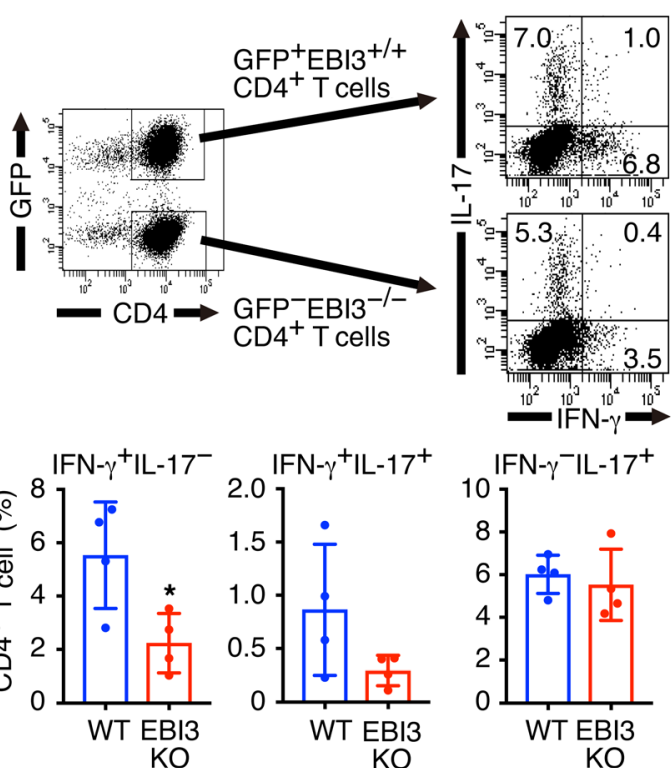
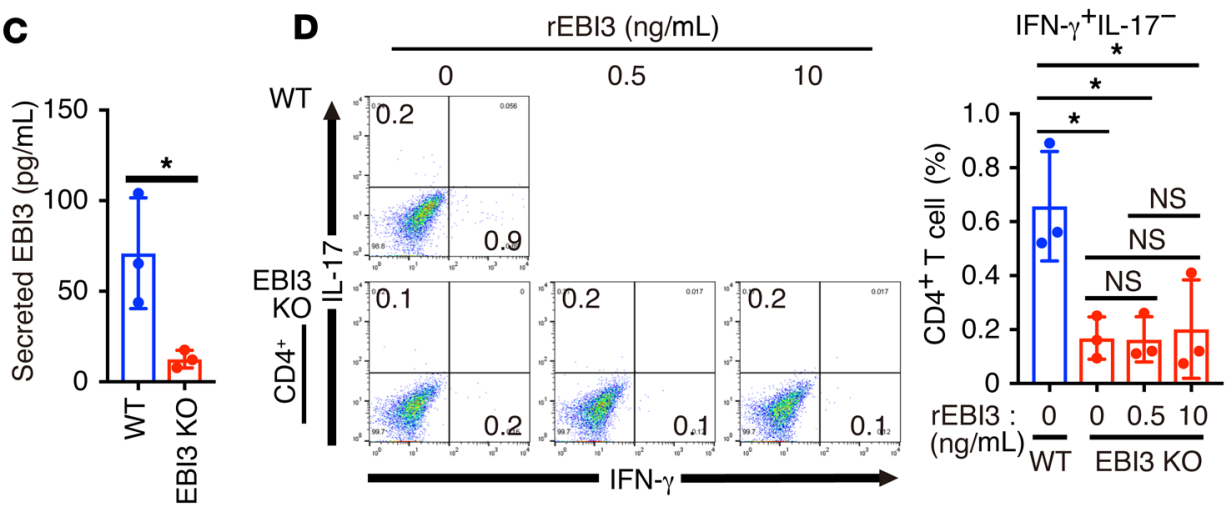

IFN- $\gamma^{-} \mathrm{IL}-17^{+}$

Figure 3. IFN- $\gamma$ production in EBI3-deficient CD4 ${ }^{+} T$ cells differentiated under pathogenic Th17 polarizing conditions with IL-23 in vitro was decreased, but not due to soluble EBI3. (A and B) Naive GFP+EBI3 ${ }^{+/+} \mathrm{CD}^{+} \mathrm{T}$ cells from green mice or GFP-EBI3 ${ }^{-1-C D 4^{+}}$T cells from EBI3-deficient mice (A) or an equal mixture of them (B) were stimulated with plate-bound anti-CD3 and anti-CD28 under pathogenic Th17 polarization conditions for 4 days. These cells were restimulated with PMA and ionomycin, and intracellular staining was performed. Representative dot plots of IFN- $\gamma$ and IL-17 in GFP+CD4 ${ }^{+} \mathrm{T}_{\text {cells }}$ or GFP-CD4+ $T$ cells are shown, and the frequencies of respective CD4+ $T$ cells were calculated. (C) Naive CD4+ $T$ cells from WT mice or EBI3-deficient mice were stimulated with plate-coated anti-CD3 and anti-CD28 under pathogenic Th17 polarizing conditions for 4 days, and culture supernatants were collected and subjected to ELISA for detection of soluble EBI3. (D) Naive CD4+ $T$ cells from WT mice or EBI3-deficient mice were similarly stimulated in the presence or absence of recombinant EBI3 for 4 days and subjected to intracellular cytokine staining. Data are shown as mean \pm SD $(n=3-4)$ and are representative of 3 independent experiments. $P$ values were determined using unpaired, 2-tailed Student's $t$ test (A-C) or 1-way ANOVA (D). ${ }^{*} P<0.05$.

under pathogenic Th17 polarizing conditions with IL-1 $\beta+$ hyperIL-6+IL-23, but not under nonpathogenic conditions with TGF- $\beta 1$ and hyper-IL-6, we next focused on molecules related to IL-23 signaling, including T-bet, STAT3, and IL-23R, which are critically important for the development of colitis (18-22). Naive CD4 ${ }^{+}$ $\mathrm{T}$ cells from WT mice or EBI3-deficient mice were stimulated in vitro with soluble anti-CD3 in the presence of irradiated WT spleen cells depleted of $\mathrm{T}$ and NK cells under pathogenic Th17 polarizing conditions with IL-1 $\beta+$ hyper-IL-6+IL-23. After 3 days, these cells were expanded with IL-2 and cultured for 2 more days. Resultant cells were restimulated with plate-bound anti-CD3 in the presence or absence of IL-23 or IL-12 for 48 hours, and culture supernatant was collected and subjected to assay for IFN- $\gamma$ and IL-17 by ELISA. In accord with the reduced frequency of IFN- $\gamma^{+}$
IL-17-CD4+ $\mathrm{T}$ cells detected by intracellular staining (Supplemental Figure 2C), IFN- $\gamma$ production was significantly decreased and IL-17 production was slightly enhanced in EBI3-deficient $\mathrm{CD} 4^{+}$ T cells (Supplemental Figure 3A). The addition of IL-23, but not IL-12, failed to further affect the production of these cytokines. IFN- $\gamma$ production in response to IL-12 was slightly reduced in the EBI3-deficient $\mathrm{CD}^{+} \mathrm{T}$ cells (Supplemental Figure 3A), but the fold increase in IFN- $\gamma$ production that was induced by IL-12 in the EBI3-deficient $\mathrm{CD} 4^{+} \mathrm{T}$ cells relative to that induced in the $\mathrm{WT}$ $\mathrm{CD}^{+} \mathrm{T}$ cells was similar or slightly higher in the EBI3-deficient $\mathrm{CD} 4^{+} \mathrm{T}$ cells than in the WT $\mathrm{CD} 4^{+} \mathrm{T}$ cells. Therefore, the absence of EBI3 may have affected IL-12 signaling, but to a lesser degree than it affected IL-23 signaling. Next, total cell lysates were prepared from these stimulated cells, and Western blot analysis was 
performed to assess the expression levels of T-bet, an upstream transcription factor for IFN- $\gamma$ production (19). In addition, further upstream signaling events through IL-23R, such as the phosphorylation level of STAT3 in response to IL-23 in the cells stimulated under pathogenic Th17 polarizing conditions (19), were determined. Correlated with the decreased IFN- $\gamma$ production, the expression levels of T-bet (Supplemental Figure 3B) and pY-STAT3 (Supplemental Figure 3, C and D) in response to IL-23 were greatly reduced in EBI3-deficient $\mathrm{CD}^{+} \mathrm{T}$ cells compared with those in WT CD $4^{+}$T cells. Thus, decreased IFN- $\gamma$ production in EBI3-deficient $\mathrm{CD} 4^{+} \mathrm{T}$ cells is highly attributed to reduced IL-23 signaling.

Decreased IFN- $\gamma$ production in EBI3-deficient $C D 4^{+} \mathrm{T}$ cells is attributed to reduced $I L-23 R \alpha$ expression. To further clarify the molecular mechanism whereby IL-23 signaling was reduced, the expression of IL-23R, which consists of IL-23R $\alpha$ and IL-12R $\beta 1$ (32), was next evaluated. Naive $\mathrm{CD} 4^{+} \mathrm{T}$ cells from WT mice or EBI3-deficient mice were stimulated with plate-bound anti-CD3 and anti-CD28 under pathogenic Th17 polarizing conditions with IL-1 $\beta+$ hyper-IL-6+IL-23. Cell lysate was then prepared at the indicated times and subjected to Western blotting (Figure 4A). EBI3 expression was rapidly increased, peaked around 4 days after stimulation, and thereafter decreased in WT CD $4^{+}$T cells. Similar but more transient augmentation of IL-23R $\alpha$ expression was observed in WT CD4 $4^{+} \mathrm{T}$ cells, whereas the augmented expression level of IL-23R $\alpha$ in EBI3-deficient $\mathrm{CD}^{+}{ }^{+} \mathrm{T}$ cells was much less than that in $\mathrm{WT} \mathrm{CD}^{+} \mathrm{T}$ cells. Intriguingly, no similarly reduced expression of IL-12R $\beta 1$, another IL-23R subunit, was detected, although its enhanced expression remained high (Figure 4A). FACS analysis also confirmed the significantly decreased MFI of cell-surface expression, as well as intracellular expression, of IL-23R $\alpha$ in EBI3-deficient CD4 ${ }^{+} \mathrm{T}$ cells (Figure 4, B and C). Moreover, in the colitis model, the cell-surface expression of IL-23R $\alpha$ and IL-12R $\beta 1$ in the $\mathrm{CD} 4^{+} \mathrm{T}$ cells of the intestinal lamina propria of RAG2-deficient mice 3 weeks after the transfer of naive CD $4^{+}$ $T$ cells was also enhanced compared with that when untransferred naive $\mathrm{CD}^{+} \mathrm{T}$ cells were used (0 week, Figure 4, D and E). However, the IL-23R $\alpha$ expression levels (but not the IL-12R $\beta 1$ levels) in RAG2-deficient mice transferred with EBI3-deficient naive CD4 ${ }^{+}$ $\mathrm{T}$ cells were significantly less than in RAG2-deficient mice transferred with WT naive CD $4^{+} \mathrm{T}$ cells, which is consistent with the in vitro results (Figure 4A). Furthermore, the retroviral infection of expression vectors of EBI3 as well as IL-23R $\alpha$ (but not the empty vector) greatly restored the decreased frequency of IFN- $\gamma^{+} \mathrm{CD} 4^{+} \mathrm{T}$ cells in EBI3-deficient $\mathrm{CD}^{+} \mathrm{T}$ cells to a level comparable to that in WT CD $4^{+} \mathrm{T}$ cells (Figure $4 \mathrm{~F}$ ). These results suggest that decreased IFN- $\gamma$ production in EBI3-deficient $\mathrm{CD}^{+}{ }^{+} \mathrm{T}$ cells is attributed to reduced IL-23R $\alpha$ expression.

Reduced IL-23R a expression in EBI3-deficient CD4 ${ }^{+} \mathrm{T}$ cells is due to synthesis of misfolded protein and therefore increased degradation of IL-23R $\alpha$ protein at proteasome. To investigate whether or not reduced IL-23R $\alpha$ expression is due to posttranscriptional effects, real-time reverse-transcription PCR (RT-PCR) analysis was performed. However, in marked contrast to the difference at the protein level, no such difference was observed at the mRNA level between WT and EBI3-deficient $\mathrm{CD} 4^{+} \mathrm{T}$ cells after stimulation (Figure 5A). Thus, the reduced expression of IL-23R $\alpha$ at the protein level is due to posttranscriptional effects. Therefore, the next step was to examine the stability of IL-23R $\alpha$ expression at the protein level, using the protein synthesis inhibitor cycloheximide. Naive $\mathrm{CD}^{+} \mathrm{T}$ cells from WT mice or EBI3-deficient mice were stimulated with plate-bound anti-CD3 and anti-CD28 under pathogenic Th17 polarization conditions for 3 days. Resultant cells were then treated with cycloheximide for the indicated times to stop de novo protein synthesis, and total cell lysates were prepared at the indicated times and subjected to Western blotting. In WT CD $4^{+} \mathrm{T}$ cells, the expression of IL-23R $\alpha$ protein was gradually decreased to the level of almost half of the initial expression during 3 hours of incubation. In marked contrast, however, in EBI3-deficient CD4 ${ }^{+}$ $\mathrm{T}$ cells, the degradation of IL-23R $\alpha$ proceeded more rapidly, and the protein was almost completely degraded within 3 hours (Figure $5, \mathrm{~B}$ and C). No similarly accelerated degradation of IL-12R $\beta 1$ was observed in EBI3-deficient $\mathrm{CD}^{+} \mathrm{T}$ cells compared with WT $\mathrm{CD} 4^{+} \mathrm{T}$ cells (Figure $5 \mathrm{~B}$ ).

Generally, there are 2 major, fundamentally different systems by which animal cells degrade proteins, the lysosome and proteasome $(33,34)$. Therefore, to determine which system degrades IL-23R $\alpha$, naive $C D 4^{+} \mathrm{T}$ cells from either WT mice or EBI3-deficient mice were stimulated with plate-bound anti-CD3 and antiCD28 under pathogenic Th17 polarization for 3 days and treated with the lysosomal protease inhibitors pepstatin A and E64d or the proteasome inhibitor MG132. Interestingly, the presence of the proteasome inhibitors, but not the lysosomal protease inhibitors, blocked the rapid degradation of IL-23R $\alpha$ in EBI3-deficient CD $4^{+}$ $\mathrm{T}$ cells, and the IL-23R $\alpha$ expression was recovered to a level similar to that in the WT CD4 ${ }^{+}$T cells (Figure 5D). Moreover, IL-23R $\alpha$ was further upregulated in the presence of both inhibitors together.

These results suggest that reduced expression of IL-23R $\alpha$ protein in EBI3-deficient CD4 ${ }^{+} \mathrm{T}$ cells is attributable to the synthesis of misfolded IL-23R $\alpha$ protein, which is readily degraded at the proteasome via ER-associated protein degradation (ERAD) (35). The IL-23R $\alpha$ whose expression level in EBI3-deficient $\mathrm{CD} 4^{+} \mathrm{T}$ cells was recovered to a level similar to that in the $\mathrm{WT}_{\mathrm{CD}} 4^{+} \mathrm{T}$ cells via the proteasome inhibitor remained misfolded and unstable and therefore became highly susceptible to even the lysosomal protease inhibitors, although these inhibitors were ineffective when used alone. Consistent with this, blue native PAGE (BN-PAGE) (36) and SDS-PAGE analyses followed by Western blotting revealed that IL-23R $\alpha$ protein synthesized in the absence of EBI3 migrates differentially from that in the presence of EBI3, suggesting it is highly likely that it is a protein with misfolded conformation (Figure 5E). Thus, EBI3 may promote the proper folding of target proteins.

Forced expression of EBI3 enhances not only intracellular expression of IL-23R $\alpha$, but also its cell-surface expression, without affecting its $m R N A$ expression. To further explore the role of EBI3 in the promotion of proper folding of IL-23R $\alpha$ protein, we next performed reconstitution experiments by using HEK293T cells transfected with expression vectors for IL-23R $\alpha$-FLAG, IL-12R $\beta 1-H A$, and EBI3. Consistent with the results obtained so far, forced expression of EBI3 greatly augmented the expression of IL-23R $\alpha$ at the protein level in a dose-dependent manner, which was detected by Western blotting (Figure 6, A and B). In marked contrast, IL-12R $\beta 1$ expression was not affected by EBI3 at all. Of note, real-time RT-PCR analysis of the transfected cells revealed that the augmentation of IL-23R $\alpha$ protein expression was not due to increased expression 
A Time after stimulation (d) :
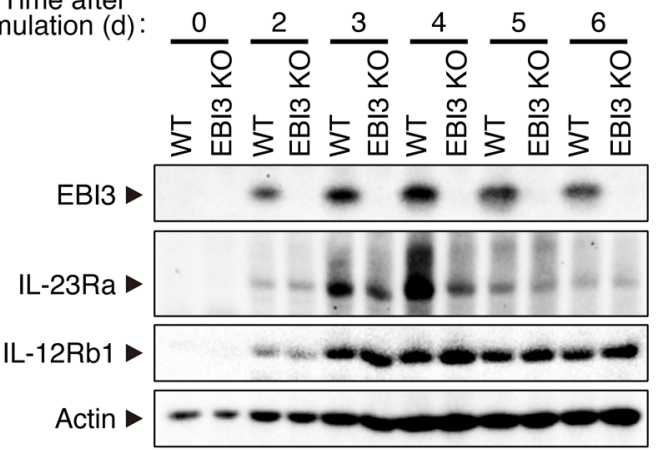

C Cell surface expression of IL-23R $\alpha$ in vitro
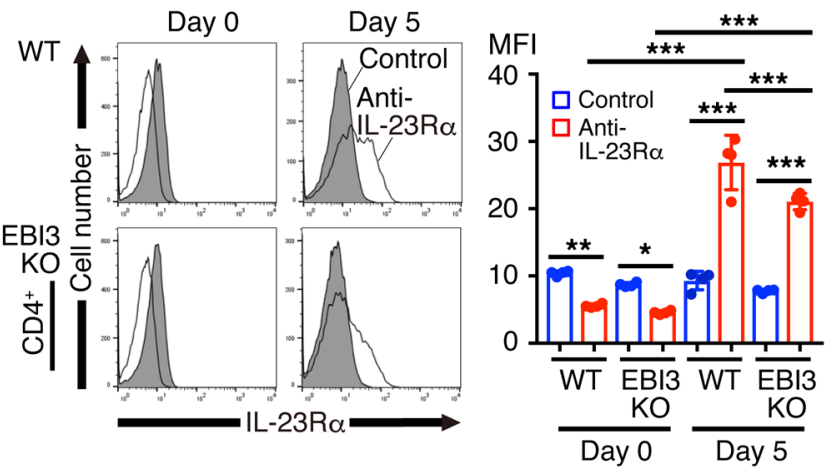

E Cell surface expression of IL-12R $\beta 1$ in vivo
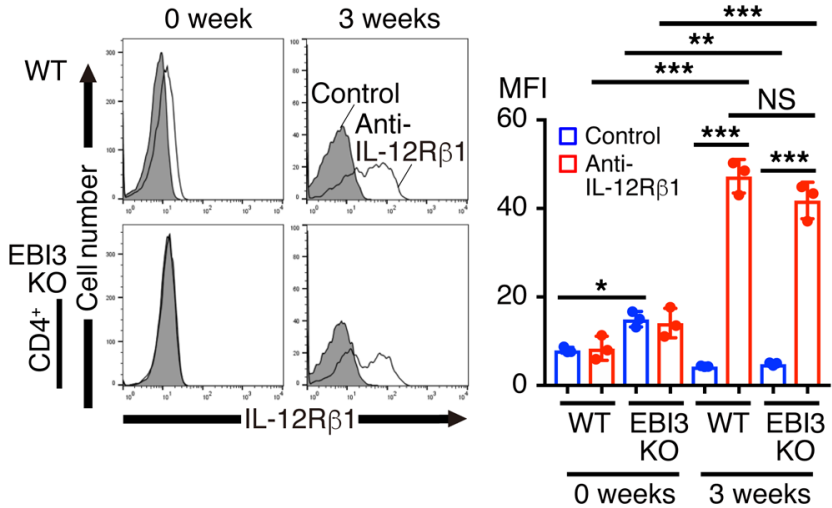

B Intracellular expression of IL-23R $\alpha$ in vitro
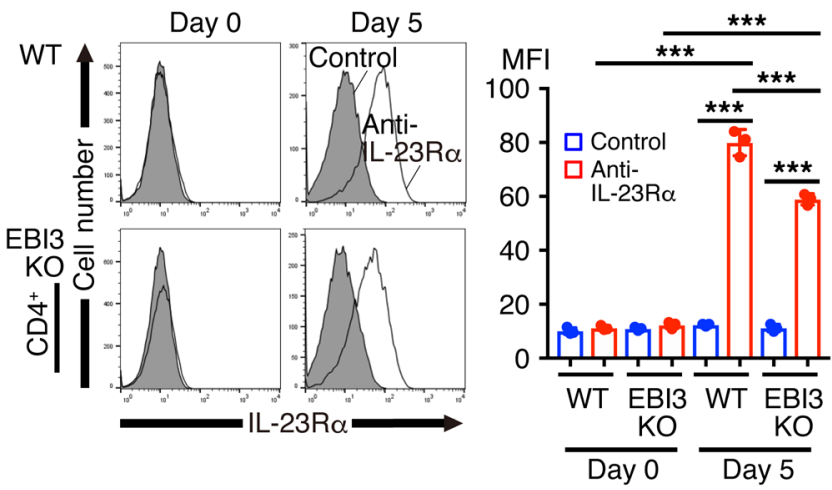

D Cell surface expression of IL-23R $\alpha$ in vivo
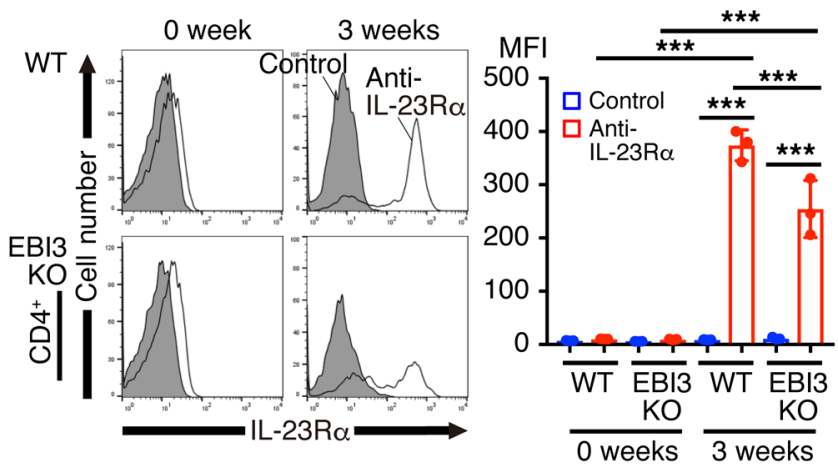

$\mathbf{F}$

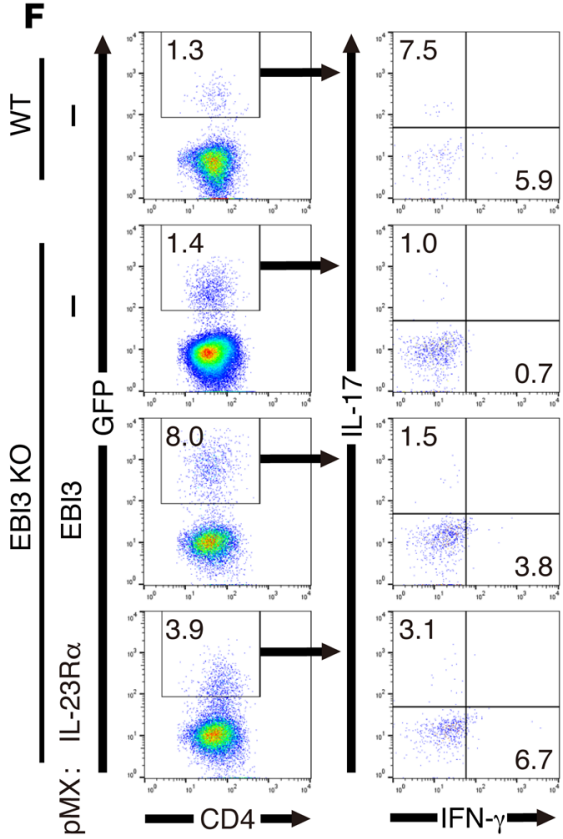

IFN- $\gamma^{+}$IL-17
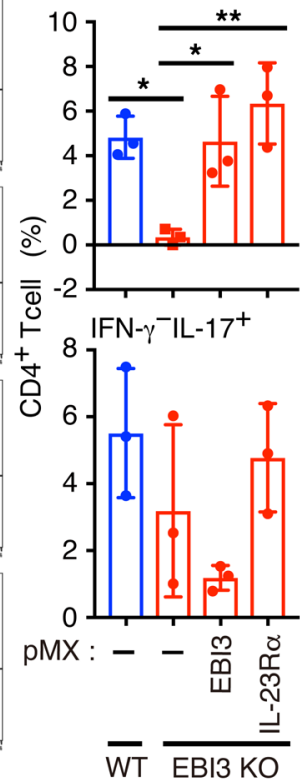

Figure 4. Decreased IFN- $\gamma$ production in EBI3-deficient CD4 ${ }^{+}$T cells attributed to reduced IL-23R $\alpha$ expression. (A-C) Naive CD4 ${ }^{+} T$ cells from WT mice or EBI3-deficient mice were stimulated with plate-bound anti-CD3 and anti-CD28 under pathogenic Th17 polarization conditions for 3 days and expanded with IL-2 for more 3 days. Total cell lysates were prepared at the indicated times after stimulation and subjected to Western blotting using antibodies against EBI3, IL-23R $\alpha$, IL-12R 1 , and actin (A). On day 5, FACS analysis for cell-surface and intracellular expression of IL-23R $\alpha$ was performed (B and C). In vivo cell-surface expression of IL-23R $\alpha$ and IL-12R $\beta 1$ in CD4+ $T$ cells of the intestinal lamina propria was also analyzed 3 weeks after transfer in the colitis model ( $\mathbf{D}$ and $\mathbf{E}$ ). Representative histograms and statistical difference in MFI are shown. (F) Retrovirally infected CD4 ${ }^{+} \mathrm{T}$ cells from EBI3-deficient mice with expression vectors of IL-23R $\alpha$, EBI3, or empty vector were stimulated under pathogenic Th17 polarizing conditions for 3 days, and frequency of IFN- $\gamma^{+} \mathrm{CD} 4^{+}$ T cells was analyzed by FACS. Data are shown as mean $\pm \mathrm{SD}(n=3$, B-F) and are representative of $3(\mathbf{A})$ or 2 (B-F) independent experiments. $P$ values were determined using 1-way ANOVA (B-F). ${ }^{*} P<0.05 ;{ }^{* *} P<0.01 ;{ }^{* *} P<0.001$. 
A
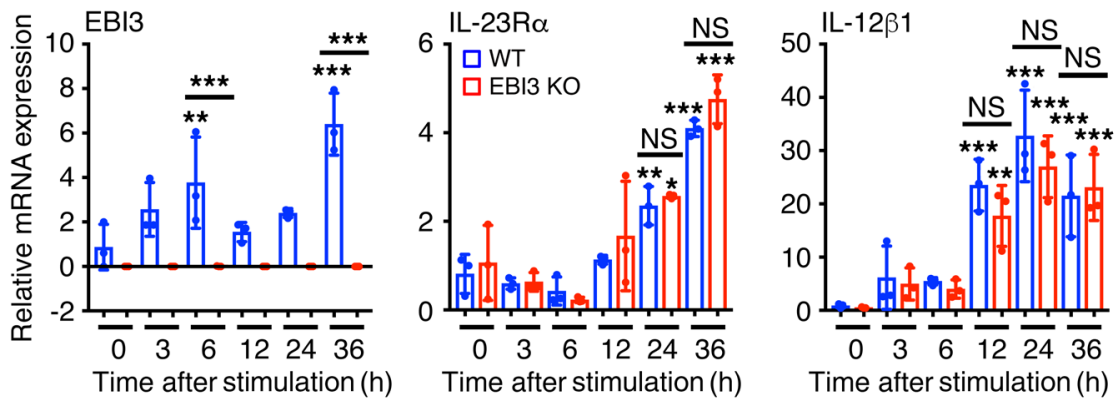

B

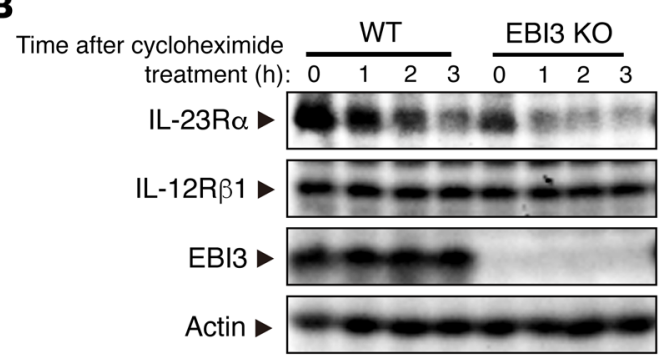

C

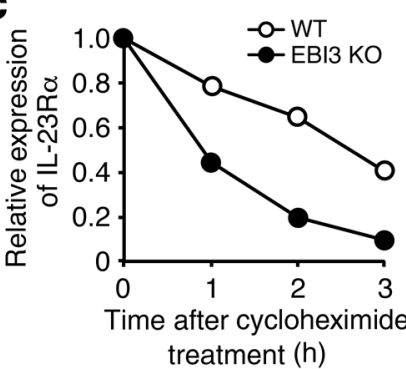

D

Day 0
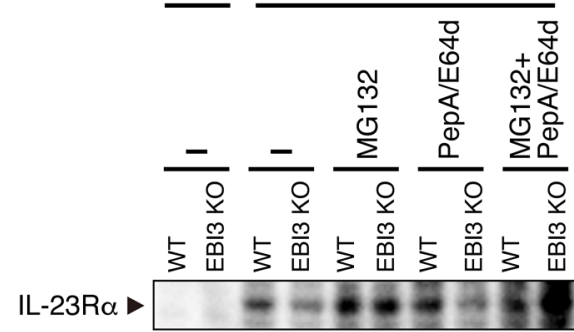

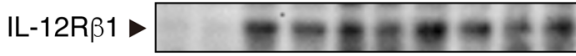

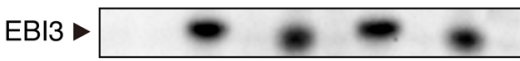

Actin
E

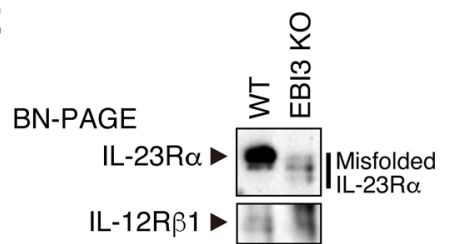

SDS-PAGE

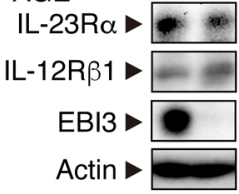

Figure 5. Reduced IL-23R $\alpha$ expression in EBI3deficient $\mathrm{CD} 4^{+} \mathrm{T}$ cells due to synthesis of misfolded protein and therefore increased degradation of IL-23R $\alpha$ protein at proteasome. (A) Naive CD4 ${ }^{+} T$ cells from WT mice or EBI3-deficient mice were stimulated with plate-bound anti-CD3 and anti-CD28 under pathogenic Th17 polarization conditions for indicated times. RNA was then prepared and subjected to real-time RT-PCR for detection of $E B I 3, I L-23 R \alpha, I L-12 R \beta 1$, and GAPDH. $C A P D H$ was used as a housekeeping gene to normalize mRNA expression. The relative mRNA expression was calculated by EBI3, IL-23R $\alpha$, or IL-12R $\beta 1$ expression per GAPDH expression. (B and C) Naive $\mathrm{CD}^{+}{ }^{+} \mathrm{T}$ cells from WT mice or EBI3-deficient mice were stimulated under pathogenic Th17 polarization conditions for 5 days and then treated with cycloheximide. After the indicated time, total cell lysates were prepared and examined for expression of IL-23R $\alpha$, IL-12R $\beta 1$, EBI3, and actin (B). Intensity of each band of IL-23R $\alpha$ and actin was quantified, and the expression of $\mathrm{IL}-23 \mathrm{R} \alpha$ was normalized to actin and is shown as the relative expression to respective time 0 (C). (D) Naive $\mathrm{CD}^{+} \mathrm{T}$ cells from WT mice or EBI3-deficient mice were stimulated under pathogenic Th17 polarization conditions for 3 days. The stimulated cells were treated with the proteasome inhibitor MG132 and the lysosomal protease inhibitors pepstatin A and E64d for the last 6 hours and 48 hours, respectively. Total cell lysates were then prepared followed by Western blotting using antibodies against IL-23R $\alpha$, IL-12R $\beta 1, E B I 3$, and actin. (E) Lysates of cells untreated with inhibitors were also analyzed by BN-PACE and SDS-PACE followed by Western blotting using anti-IL-23R $\alpha$. Each blot was run in parallel and contemporaneously. Data are shown as mean $\pm \operatorname{SD}(n=3, \mathbf{A})$ and are representative of $3(\mathbf{A})$ or 2 (B-E) independent experiments. $P$ values were determined using 1-way ANOVA (A). ${ }^{* *} P<0.01 ;{ }^{* *} P<0.001$. of IL-23R $\alpha$ mRNA (Figure 6C). Immunohistochemical analysis further revealed that forced expression of EBI3 augmented not only the intracellular expression of IL-23R $\alpha$ (Figure 6D), but also its cell-surface expression (Figure 6E). In the intracellular staining analysis, anti-calnexin antibody was used as a marker for the $\mathrm{ER}$, but colocalization was prominent among IL-23R $\alpha, \mathrm{EBI} 3$, and calnexin (Figure 6D), suggesting that calnexin may be involved in augmenting EBI3-mediated IL-23R $\alpha$ expression. To more precisely and quantitatively analyze the expression of IL-23R $\alpha$, the bicistronic IRES-GFP vector of $N$-terminal FLAG-tagged IL-23R $\alpha$ was transiently cotransfected with EBI3 expression vector or its control empty vector into AD293 cells and subjected to flow cytometry analysis. The $\mathrm{GFP}^{+}$populations correspond to the populations transduced with the IL-23R $\alpha$ expression vector. Intracellular and cell-surface expression of IL-23R $\alpha$ in the $\mathrm{GFP}^{+} \mathrm{EBI}^{-}$populations transduced with the control empty vector and the $\mathrm{GFP}^{+} \mathrm{EBI} 3^{+}$populations transduced with EBI3 expression were compared (Figure 6 , F and G). Consistent with the results obtained by immunohistochemical analysis (Figure 6, D and E), MFI of the intracellular expression of IL-23R $\alpha$ was greatly increased by the presence of EBI3 (Figure 6F). Moreover, MFI of its cell-surface expression was also significantly increased by the presence of EBI3 (Figure 6G). In line with these results, enhanced signaling through the IL-23R in response to IL-23 was subsequently detected by luciferase activity after cotransfection with the IL-23-responsive IFN- $\gamma$-activated site (GAS) luciferase construct p3xGAS-Luc (ref. 37 and Figure $6 \mathrm{H})$. These results suggest that forced expression of EBI3 enhances not only intracellular expression of IL-23R $\alpha$, but also its cell-surface expression, without affecting its mRNA expression.

$E B I 3$ binds to calnexin and $I L-23 R \alpha$, and calnexin is necessary for the EBI3-mediated augmentation of IL-23Ra protein expression. The results obtained so far prompted us to presume that EBI3 may be able to promote the proper folding of protein, so we next explored the involvement of calnexin in the augmentation of IL-23R $\alpha$ protein expression by EBI3. This step was taken because calnexin is a well-characterized lectin chaperone involved in the proper folding of newly synthesized glycoproteins in the lumen of the ER (25-27). In addition, EBI3 was initially identified not only as a secreted molecule, but also in association with calnexin in the ER, although its physiological and functional roles remain unknown (2).

Therefore, we next determined whether EBI3 can bind to endogenous calnexin and IL-23R $\alpha$ by using transfection with 
A

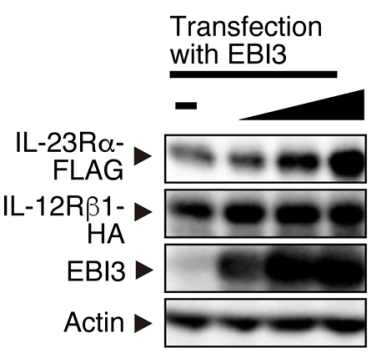

B

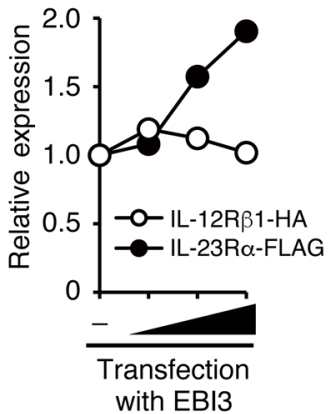

D

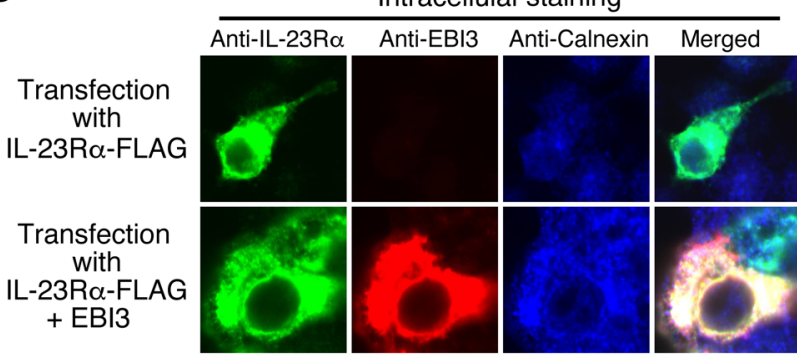

C

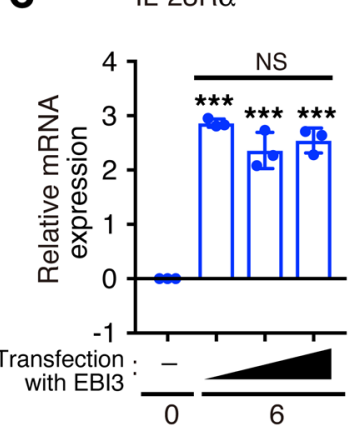

IL-12R 11

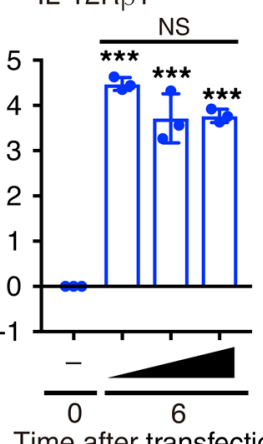

EBI3

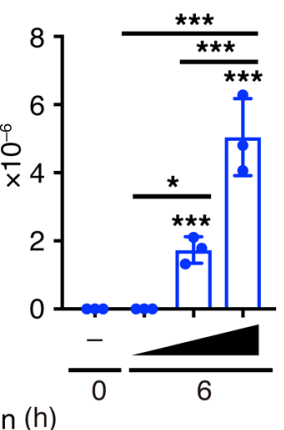

E

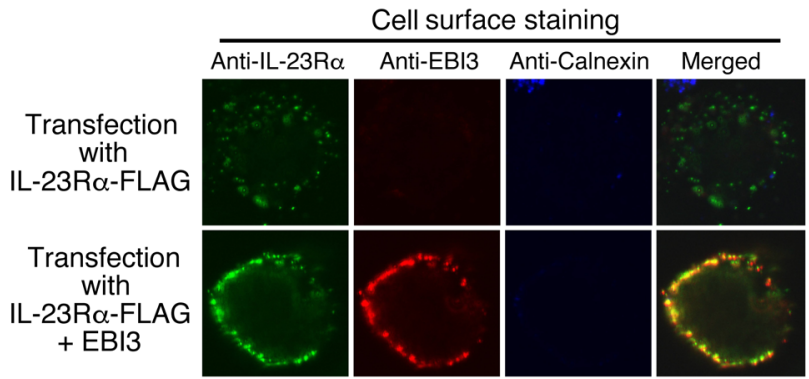

F Intracellular expression

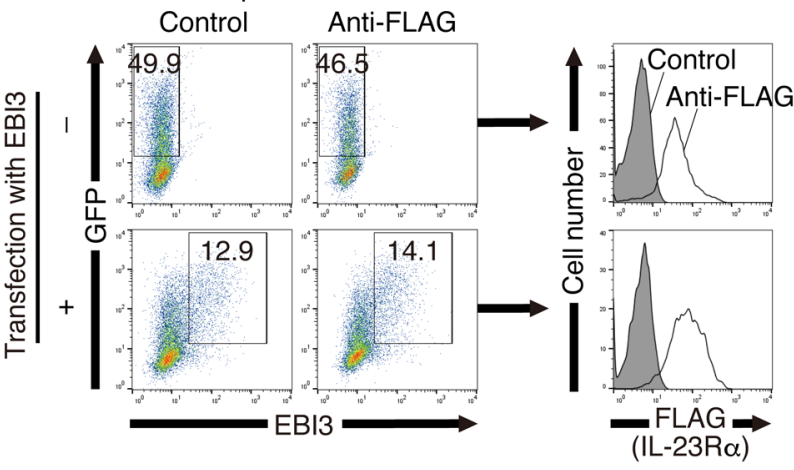

G Cell surface expression

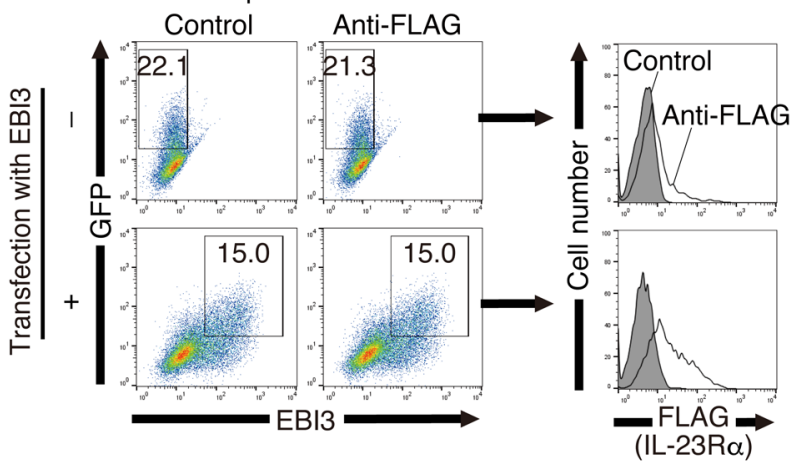

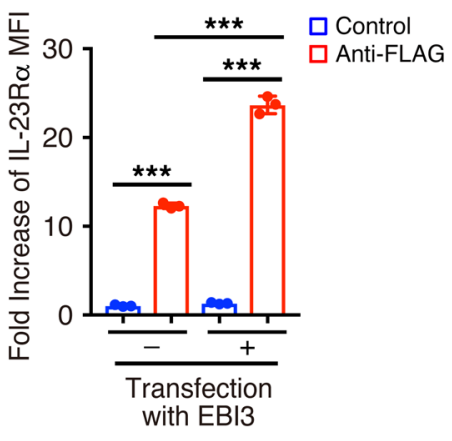

H
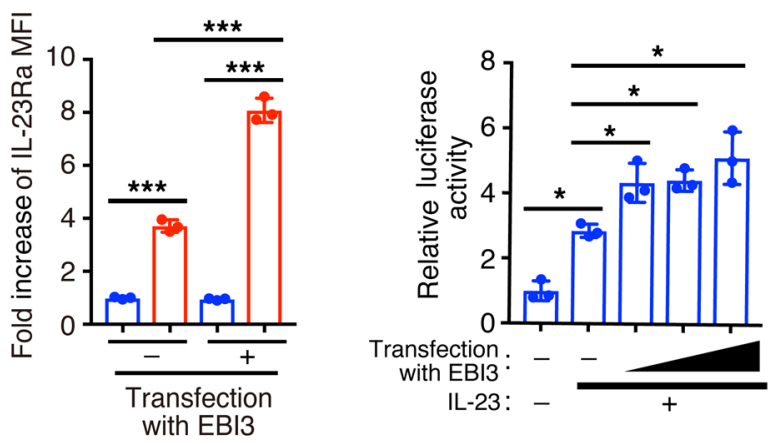
Figure 6. Forced expression of EBI3 enhances not only intracellular expression of IL-23R $\alpha$, but also its cell-surface expression, without affecting its mRNA expression. (A-C) HEK293T cells were transfected with expression vectors of IL-23R $\alpha$-FLAG, IL-12R $\beta 1-H A$, and EBI3, and 72 hours later total cell lysates were prepared, followed by Western blotting (A). Intensity of each band was quantified, and the expression of IL-23R $\alpha$ and IL-12R $\beta 1$ was normalized to actin and is shown as the relative expression to respective untransfection (B). RNA was also prepared 6 hours after the stimulation and subjected to quantitative RT-PCR (C). GAPDH was used as a housekeeping gene to normalize each mRNA expression. ( $\mathbf{D}$ and $\mathbf{E}$ ) The transfected HEK293T cells were also intracellularly fixed and stained for IL-23R $\alpha, E B I 3$, and calnexin (D). For cell-surface staining, the fixation procedure was omitted (E). Representative photographs are shown. Original magnification, $\times 600$. (F and $\mathbf{G})$ AD293 cells were transfected with expression vectors of FLAG-IL-23R $\alpha$ IRES-GFP and EBI3, and 72 hours later cells were fixed and intracellularly stained for FLAG-IL-23R $\alpha$ and EBI3 (F). Cells were also stained for cell-surface expression of FLAG-IL-23R $\alpha$ followed by intracellular staining for $\mathrm{EBI3}$ (G). Representative dot plots of GFP and EBI3, and histograms of FLAG-IL-23R $\alpha$ in $\mathrm{GFP}^{+} \mathrm{EBI} 3^{-}$and $\mathrm{GFP}^{+} \mathrm{EBI} 3^{+}$cells are shown, and the fold increase of MFI of FLAG-IL-23R $\alpha$ expression was calculated. (H) HEK293T cells were transfected with expression vectors of IL-23R $\alpha$-FLAC, IL-12R $\beta 1-H A, E B I 3,3 x G A S-L u c$, and RL-TK, and 48 hours later, these cells were stimulated with IL-23 for more 6 hours. Total cell lysates were then prepared, and luciferase activity was measured and is shown as relative activity. Data are shown as mean $\pm S D(n=3, C$ and $\mathbf{F}-\mathbf{H}$ ) and are representative of 3 independent experiments. $P$ values were determined using 1-way ANOVA (C and F-H). ${ }^{*} P<0.05$; ${ }^{* *} P<0.001$.

expression vectors of IL-23R $\alpha$-FLAG and EBI3. Without EBI3, IL-23R $\alpha$ bound to endogenous calnexin, possibly through glycochain interaction (Figure 7A). Increasing amounts of EBI3 led to its association with endogenous calnexin as well as IL-23R $\alpha$ (Figure 7A). Because calnexin is well known as binding to its target protein through glycochain interaction, the sensitivity to tunicamycin, an inhibitor of glycosylation, was examined next. Treatment with tunicamycin had little impact on the association between EBI3 and endogenous calnexin (Supplemental Figure 4A). In contrast, the treatment greatly increased the amounts of faster migrating bands, which likely represent nonglycosylated species, of IL-23R $\alpha$ immunoprecipitated with EBI3 (Supplemental Figure 4A). These results suggest that EBI3 binds to calnexin and IL-23R $\alpha$ in a peptide-dependent but not glycan-dependent manner.

To examine the role of calnexin in the EBI3-mediated augmentation of IL-23R $\alpha$ expression, HEK293T cells were then transfected with expression vectors of IL-23R $\alpha$-FLAG, IL-12R $\beta 1-H A$, EBI3, and mouse calnexin-MYC. In the absence of EBI3, mouse calnexin alone enhanced the expression of IL-23R $\alpha$ (Supplemental Figure 4, B and C). Increasing amounts of EBI3 further augmented the expression of IL-23R $\alpha$, but not IL-12R $\beta 1$, in the presence of mouse calnexin (Supplemental Figure 4, B and C). Similar additive effects between EBI3 and mouse calnexin on the augmentation of both intracellular and cell-surface expression of IL-23R $\alpha$ were observed by immunohistochemical analysis (Figure 7, B and C).

Next, the necessity of calnexin for the EBI3-mediated augmentation of IL-23R $\alpha$ proteins was evaluated in HEK293T cells whose endogenous calnexin expression was knocked out by genome editing with the CRISPR/Cas9 method (38). In WT HEK293T cells, forced expression of EBI3 augmented the expression of IL-23R $\alpha$ in a dose-dependent manner (Figure 7, D and E). In contrast, in the calnexin-KO HEK293T cells, forced expression of EBI3 did not augment the expression of IL-23R $\alpha$ at all, which was determined by Western blotting with both anti-FLAG and anti-IL-23R $\alpha$ (Figure 7, D and E). Similar results were obtained by using HEK293T cells whose endogenous calnexin expression was knocked down to $40 \%$ by its specific siRNA (Supplemental Figure 5, A and B).

To further examine the association among EBI3, IL-23R $\alpha$, and calnexin in primary cells instead of overexpressing cells, WT naive $\mathrm{CD}^{+} \mathrm{T}$ cells were stimulated under pathogenic Th17 polarizing conditions for 3 days. The resultant cell lysates were then used for immunoprecipitation analyses with anti-EBI3 followed by Western blotting with anti-IL-23R $\alpha$ or anti-calnexin. Consistent with the results of the overexpressing cells (Figure 7A), similar binding of EBI3 to IL-23R $\alpha$ or calnexin (Figure $7 \mathrm{~F}$ ) was observed in primary $\mathrm{CD}^{+} \mathrm{T}$ cells. These results suggest that EBI3 binds to IL-23R $\alpha$ and calnexin in a peptide-dependent, but not glycan-dependent, manner and that calnexin is necessary for the EBI3-mediated augmentation of IL-23R $\alpha$ protein expression.

$E B I 3$ binds to the extracellular region of $I L-23 R \alpha$ but not its protective variant $G 149 R$, against IBD due to reduced binding of EBI3 to the variant. Finally, the site in the IL-23R $\alpha$ molecule where EBI3 binds was investigated. Immunoprecipitation analysis revealed that EBI3 not only bound to full-length IL-23R $\alpha$, but also the extracellular region of IL-23R $\alpha$, so-called soluble IL-23R $\alpha$ (sIL$23 \mathrm{R} \alpha$, Figure $8 \mathrm{~A}$ ). Consistent with these results, interestingly, flow cytometry analysis demonstrated that forced expression of EBI3 in HEK293-F cells resulted in markedly increased expression of EBI3 on the cell surface (2). In addition, coexpression of EBI3 with IL-23R $\alpha$, but not IL-12R $\beta 1$, further enhanced the cell-surface expression of EBI3 (Figure 8B). These results suggest that EBI3 binds to the extracellular region of IL-23R $\alpha$.

Recently, genome-wide association studies and targeted resequencing studies revealed that the IL-23R $\alpha$ variants G149R, V362I, and R381Q are linked to protection against the development of IBD in humans because of their impaired protein stability and the resultant decreased signaling by IL-23 (28). Among these variants, only G149R is located in the extracellular region of IL-23R $\alpha$, which prompted us to examine the possibility that this site might be where EBI3 binds. After transfection with expression vectors of FLAG-IL-23R $\alpha$ WT or FLAG-IL-23R $\alpha$ G149R and of EBI3, immunohistochemical analysis was performed. As shown before (Figure $5 \mathrm{E}$ ), forced expression of EBI3 augmented the cell-surface expression of IL-23R $\alpha$ WT (Figure $8 \mathrm{C}$ ). However, in marked contrast, forced expression of EBI3 augmented the cell-surface expression of IL-23R $\alpha$ G149R much less efficiently, although the expression level of IL-23R $\alpha$ G149R in the absence of EBI3 was also less than that of IL-23R $\alpha$ WT, as previously reported (ref. 28 and Figure $8 \mathrm{C})$. To more precisely and quantitatively analyze the expression of IL-23R $\alpha$, the bicistronic IRES-GFP vector of FLAG-IL-23R $\alpha$ WT or its G149R variant was transiently cotransfected with EBI3 expression vector or its control empty vector and subjected to flow cytometry analysis. Cell-surface expression of WT IL-23R $\alpha$ or its G149R variant in the $\mathrm{GFP}^{+} \mathrm{EBI}^{-}$populations transduced with the control empty vector and the $\mathrm{GFP}^{+} \mathrm{EBI}^{+}$populations transduced with the EBI3 expression were compared (Figure 8, D and E). Consistent with the results obtained by immunohistochemical analysis (Figure 8C), MFI of the cell-surface expression of WT IL-23R $\alpha$ was greatly increased by the presence of EBI3. However, 
A
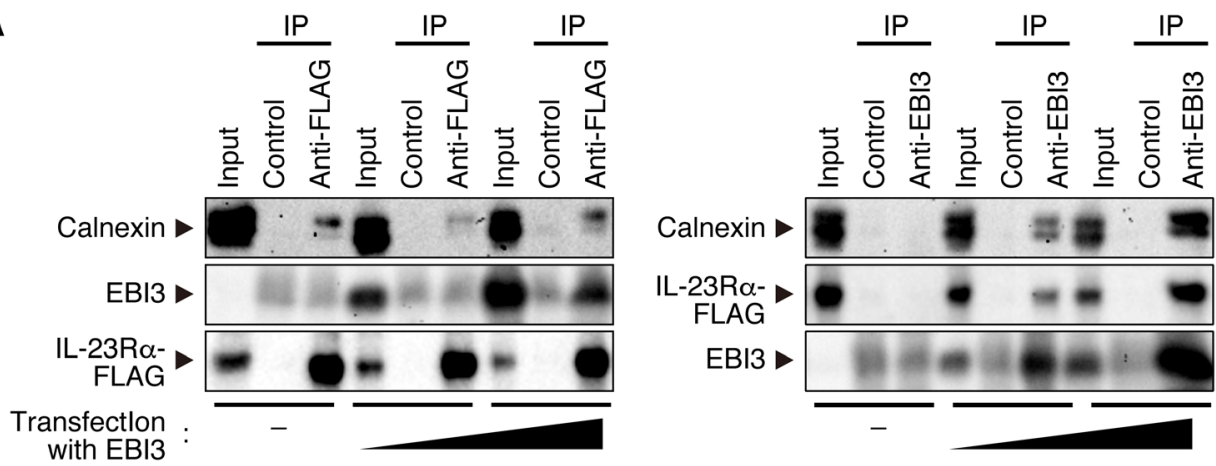

B

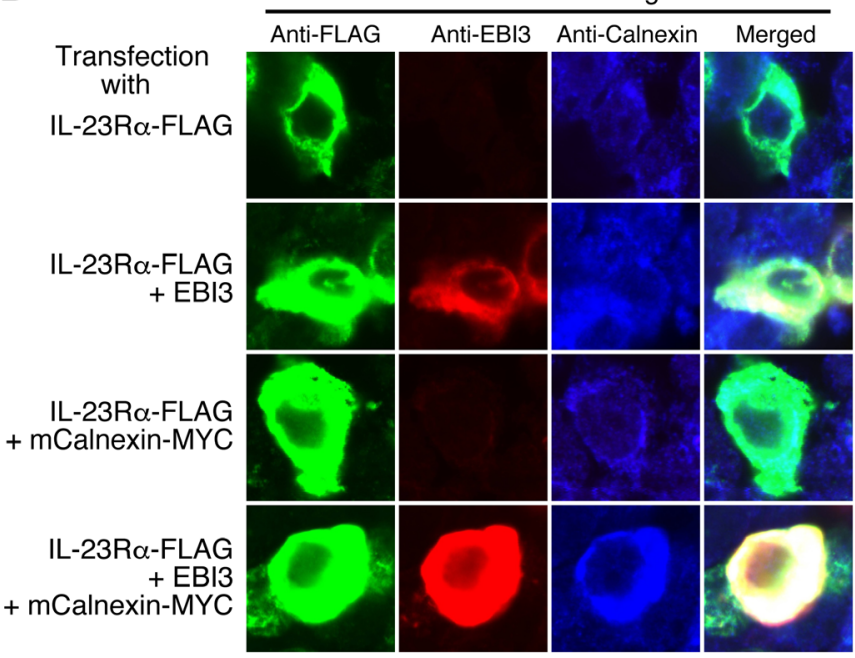

C

Cell surface staining

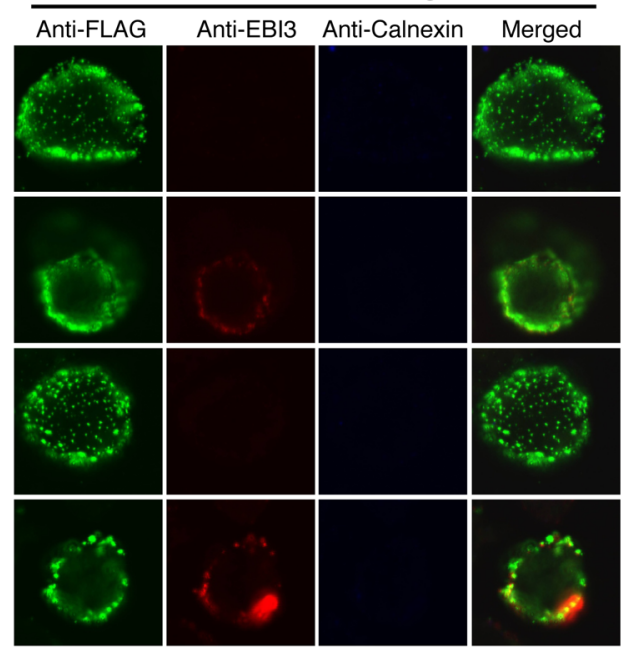

D

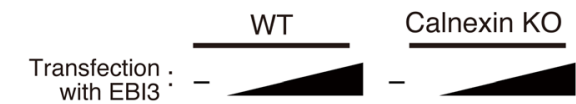

\section{E}

Detected by anti-FLAG
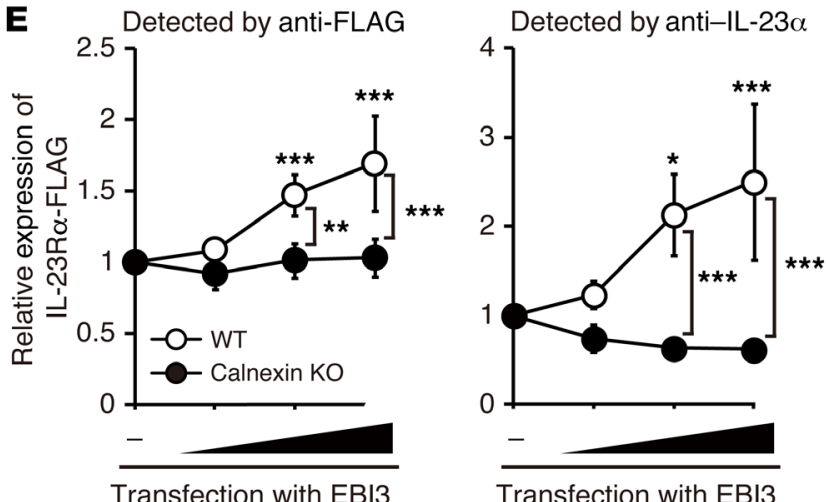

Calnexin

Actin
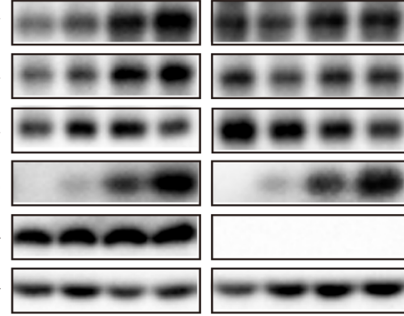

detected by

Anti-IL-23R $\alpha$
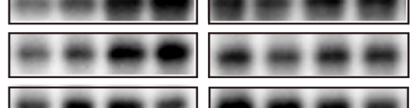

-12R $\beta 1-\mathrm{HA}$

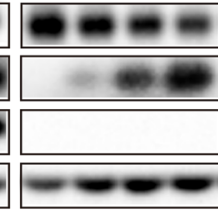

F IP

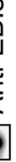

$\mathrm{IL}-23 \mathrm{R} \alpha \longrightarrow$ EBI3 $\square$ $\frac{\text { IP }}{\text { D. }}$

Calnexin --1 EBI3 $\square$
Figure 7. EBI3 binds to calnexin and IL-23R $\alpha$, and calnexin is necessary for the EBI3-mediated augmentation of IL-23R $\alpha$ protein expression. (A) HEK293T cells were transfected with expression vectors of IL-23R $\alpha$-FLAG and EBI3, and 48 hours later, total cell lysate was prepared and subjected to immunoprecipitation with anti-FLAG or anti-EBI3, followed by Western blotting with anti-calnexin, anti-EBI3, and anti-FLAG, as indicated. (B and C) HEK293T cells were transfected with expression vectors of IL-23R $\alpha-F L A G, E B I 3$, and mouse calnexin-MYC, and 72 hours later, cells were fixed for intracellular staining of IL-23R $\alpha$ using anti-IL-23R $\alpha$ followed by secondary antibody conjugated with Alexa Fluor 488, for EBI3 using anti-EBI3 followed by secondary antibody conjugated with Alexa Fluor 594 , and for calnexin using anti-calnexin followed by secondary antibody conjugated with Alexa Fluor 647 (B). For cell-surface staining, the fixation procedure was omitted (C). Representative photographs are shown. Original magnification, $\times 600$. (D and E) WT and calnexin KO HEK293T cells were transfected with expression vectors of IL-23R $\alpha$-FLAG, IL-12R $\beta 1-H A$, and EBI3. After 72 hours, total cell lysate was prepared for Western blotting. (D), intensity of each band of IL-23R $\alpha$-FLAG was detected by anti-FLAG or anti-IL-23R $\alpha$, and actin was quantified, and the expression of IL-23R $\alpha$-FLAG was normalized to actin and is shown as the relative expression to respective untransfection (E). (F) Immunoprecipitation analyses with anti-EBI3 followed by Western blotting with anti-IL-23R $\alpha$ or anti-calnexin were performed using cell lysates of WT naive CD4+ $T$ cells stimulated under pathogenic Th17 polarizing conditions for 3 days. Note each blot was run in parallel and contemporaneously. Data are shown as mean $\pm S D(n=3, \mathbf{D}$ and $\mathbf{E})$ and are representative of 2 (D-F) or $3(\mathbf{A}-\mathbf{C})$ independent experiments. $P$ values were determined using unpaired, 2-tailed Student's $t$ test (E). ${ }^{*} P<0.05 ;{ }^{*} P<0.01 ;{ }^{* *} P<0.005$. 

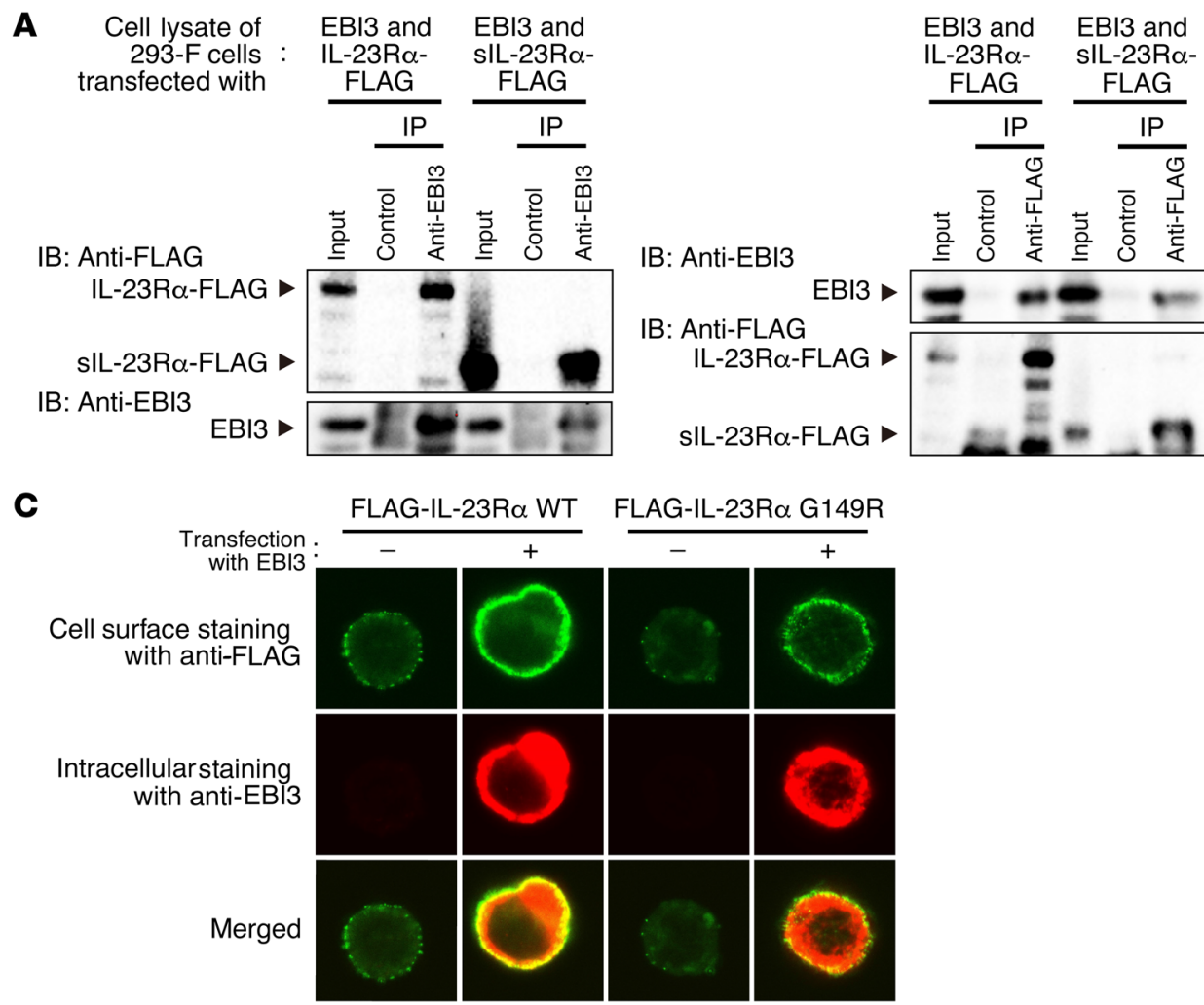
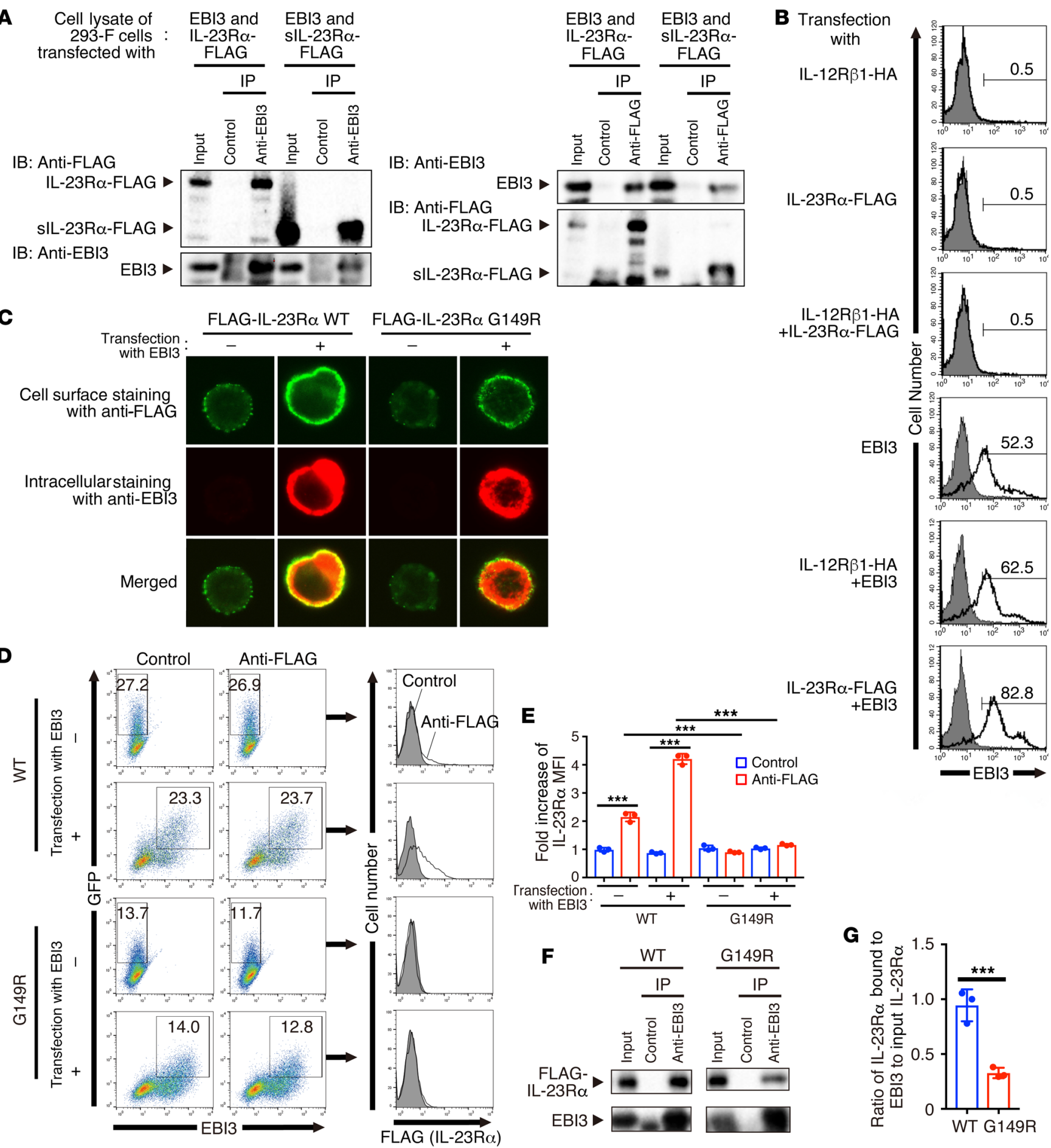

E
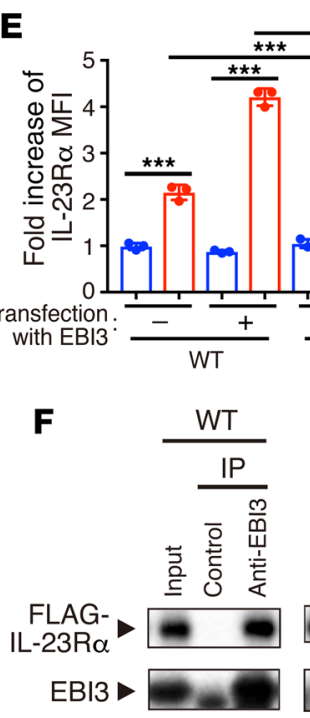

G 요

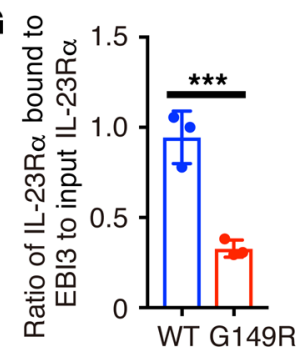

Figure 8. EBI3 binds to the extracellular region of IL-23R $\alpha$, but not its protective variant G149R, due to reduced binding of EBI3 to the variant. (A) HEK293-F cells were transfected with expression vectors of IL-23R $\alpha$-FLAG or sIL-23R $\alpha$-FLAG and EBI3 and, 48 hours later, subjected to immunoprecipitation followed by Western blotting. (B) HEK293-F cells were transfected with expression vectors of IL-12R $11-\mathrm{HA}$, IL-23R $\alpha$-FLAG, and EBI3, and 48 hours later, cell-surface expression of EBI3 was analyzed by flow cytometry using anti-EBI3 (solid line) or control antibody (plain line with shading). Numbers indicate percentage of EBI3+ cells. (C) HEK293T cells were transfected with expression vectors of FLAG-IL-23R $\alpha$ WT or FLAG-IL-23R $\alpha$ G149R and EBI3, and 48 hours later, cells were stained for cell-surface expression of IL-23R $\alpha$ and then fixed and stained for intracellular expression of EBI3. Original magnification, $\times 600$. (D and E) AD293 cells were transfected with expression vectors of FLAG-IL-23R $\alpha$-IRES-GFP WT or FLAG-IL-23R $\alpha$ G149R-IRES-GFP and EBI3, and 72 hours later, cells were stained for cell-surface expression of IL-23R $\alpha$ and intracellular expression of EBI3. Representative dot plots and histograms of FLAG-IL-23R $\alpha$ in GFP+EBI3- and GFP+EBI3+ cells are shown (D), and the fold increase of MFI of FLAG-IL-23R $\alpha$ expression was calculated (E). (F and G) HEK293T cells were transfected with expression vectors of FLAG-IL-23R $\alpha$ WT or FLAG-IL-23R $\alpha$ G149R and EBI3 and, 48 hours later, subjected to immunoprecipitation with anti-EBI3 followed by Western blotting with anti-FLAC (F). The intensity of each band was quantified, and the expression of IL-23R $\alpha$ was normalized to EBI3 and is shown as the ratio of IL-23R $\alpha$ bound to EBI3 to input IL-23R $\alpha$ (C). Data are shown as mean $\pm S D(n=3, \mathbf{D}-\mathbf{C})$ and are representative of 3 independent experiments. $P$ values were determined using 1-way ANOVA (E) or unpaired, 2-tailed Student's $t$ test (G). ${ }^{* *} P<0.005$. 
MFI of the cell-surface expression of its G149R variant was barely increased by the presence of EBI3. Consistent with these results, immunoprecipitation analysis revealed that the binding of EBI3 to IL-23R $\alpha$ G149R was greatly decreased compared with its binding to IL-23R $\alpha$ WT (Figure 8, F and G).

Taken together, these results indicate that EBI3 binds to the extracellular region of IL-23R $\alpha$, but fails to augment the protein expression of IL-23R $\alpha$ protective variant G149R against IBD because of reduced binding of EBI3 to the variant. Thus, EBI3 could play a critical role in the augmentation of IL-23R $\alpha$ protein expression in humans, which determines the susceptibility to IBD development.

\section{Discussion}

EBI3 was originally identified as a molecule related to IL-12 p40 whose expression is induced by latent EBV infection in B lymphocytes (2). IL-12 p40 forms a disulfide-linked heterodimer with p35 to produce functional IL-12, and a homodimeric form of p40 is also produced in excess $(39,40)$. In marked contrast, however, EBI3 has 4 cysteines and all of them are likely to be used for intramolecular disulfide linkage. Therefore, EBI3 lacks the additional cysteines that are necessary for heterodimerization with other molecules, as $\mathrm{p} 40$ forms a heterodimer with p35 through disulfide linkage. In addition, EBI3 was shown to also be present on the plasma membrane of cells transfected with EBI3 cDNA, as shown in Figure 7B, possibly suggesting that EBI3 can associate with other membrane proteins (2). Intriguingly, EBI3 was previously demonstrated to associate with calnexin (2), an integral ER membrane calcium-binding lectin chaperone (25-27), although further functional studies are needed. Calnexin binds immature membrane glycoproteins destined for the plasma membrane, and it supports folding and maturation of these proteins. Calnexin retains protein in the ER until proper folding of protein occurs, after which the protein enters the secretory pathway; otherwise, calnexin targets misfolded proteins for degradation via ERAD, which is a proteasome-mediated process (35). Thus, EBI3 may be able to associate with other molecules that are not efficiently transported to the cell surface or secreted alone. Indeed, EBI3 noncovalently associates with p28, p35, and p19 to form IL-27 (3), IL-35 (4), and IL-39 (5), respectively. In line with the properties of EBI3 mentioned above, we have herein uncovered an important role for EBI3 in the promotion of proper protein folding of IL-23R $\alpha$ by binding to calnexin and IL-23R $\alpha$ through peptide interactions, leading to the development of colitis. Proteasomal degradation is also known to occur in cytokine receptors after internalization and ubiquitination by ligand binding (41). Whether EBI3 can also regulate such proteasomal degradation of IL-23R $\alpha$ remains to be elucidated.

Calnexin is ubiquitously and constitutively expressed in various types of cells to chaperone membrane glycoprotein expression, whereas EBI3 expression is inducible mainly via NF- $\kappa \mathrm{B}$ activation in response to various stimuli, including Toll-like receptor ligands (42) and also via activation through the T cell receptor (Figure 1A). Therefore, EBI3 plays a role under inflammatory conditions, but not under steady-state conditions, in augmenting target proteins, whose expression is also inducible. However, among such inducible proteins, including IL-23R $\alpha$ and IL-12R $\beta 1$, EBI3 augments the protein expression of IL-23R $\alpha$ only, not IL-12R $\beta 1$. The expression of other inducible proteins that are known to regulate IL-23R $\alpha$ expression and the resultant STAT3 activation, c-Maf (43) and SOCS3 (44), respectively, was not augmented by EBI3 (Supplemental Figure 6). One reason for this difference is that EBI3 can bind to IL-23R $\alpha$, but not IL-12R $\beta 1$ (data not shown). Therefore, several issues remain to be resolved, including determination of the molecular mechanism whereby EBI3 selectively augments its target protein expression, the identity of other possible target molecules, and any relationship between the polymorphism of EBI3 itself and susceptibility to IBD in humans. Indeed, several polymorphisms of EBI3 have been reported to be associated with cancers and immune disorders, including IBDs, such as ulcerative colitis (45). In addition, upregulation of EBI3 expression in colonic tissue was demonstrated in patients with IBD (46-48). Moreover, EBI3-deficient mice were previously reported to be resistant to the development of immunopathology associated with a mouse colitis model induced by oxazolone, whereas the same EBI3-deficient mice showed no changes in intestinal pathology in trinitrobenzene sulfonic acid-induced colitis (49). Considering that EBI3 is also a subunit shared by IL-27, IL-35, and IL-39, which have redundant and opposite functions (50), it is not easy to simply conclude that there is a specific relationship between EBI3 and IBD. In addition, because EBI3 was previously demonstrated to be predominantly and constitutively expressed in placenta among various normal human tissues (2), identification of its target molecule in the placenta might lead to further elucidation of a specific role for EBI3 in the functions of placenta. For such tissue- or cell type-specific analysis of EBI3, EBI3 reporter mice, which were developed by Vignali's group (51), would be very useful.

EBI3-deficient mice have been reported as showing several phenotypes, which may or may not be explained by the roles of either IL-27, IL-35, or IL-39. EBI3-deficient mice promoted the development of experimental autoimmune encephalomyelitis due to increased Th17, Th1, IL-2, and Treg responses, which seems to be consistent with the functions of IL-27, but not IL-35 (52). In contrast, EBI3-deficient mice developed early severe intestinal disease, whereas IL-27 p28-deficient mice were phenotypically similar to WT mice, suggesting that IL-35 rather than IL-27 is a critical factor limiting intestinal inflammation in the model of $\mathrm{T}$ cell-dependent colitis (53). Although both mouse disease models were sensitive to IL-23, the distinct roles of EBI3 might also be due to the different susceptibilities of these disease models to IL-23 responsiveness. Both phenotypes of EBI3-deficient mice in these reports appear to include enhanced Th1-like responses and IFN- $\gamma$ production, which seems to oppose the intracellular role of EBI3 in $\mathrm{CD}^{+} \mathrm{T}$ cells, as clarified in the present study. However, in marked contrast, there are also several papers showing reduced Th1-like responses and IFN- $\gamma$ production in EBI3-deficient mice under various situations (54-57). Interesting papers have recently been published showing the roles of IL-27 and soluble EBI3 in CD4 ${ }^{+} \mathrm{T}$ cells and the intracellular role of EBI3 in macrophages. IL-27 was shown to be produced by $\mathrm{CD} 4^{+} \mathrm{T}$ cells to regulate the protective immune response against malaria parasites (58). In addition, it was very recently demonstrated that EBI 3 is secreted by activated $\mathrm{CD}^{+} \mathrm{T}$ cells and promotes $\mathrm{T}$ cell division and differentiation via the gp130/STAT3 signaling pathway in an autocrine manner (31). The intracellular function of EBI3 was also very recently reported, as the infection of macrophages with virulent mycobacteri- 
um tuberculosis accumulates intracellular EBI3 by the binding of eukaryotic translation elongation factor 1- $\alpha 1$ (eEF1A1) to EBI3 to reduce Lys48-linked ubiquitination of EBI3, resulting in the inhibition of caspase-3-mediated apoptosis (59). We also cannot deny the possibility that EBI3 may also bind to other molecules that have not yet been identified. The results obtained from EBI3-deficient mice come from the sum of the respective positive and negative effects of IL-27, IL-35, IL-39, soluble and intracellular EBI3, and so on; it is therefore difficult to reduce this to a simple conclusion based only on results obtained from EBI3-deficient mice without any contradiction.

Similar seemingly conflicting results on the tumor growth in one of the transplantable mouse tumor models, B16F10 melanoma, in EBI3-deficient mice were also reported. EBI3-deficient mice were shown to exert augmented immunosurveillance against metastasis of lung B16F10 melanoma, which was mediated by T-bet-mediated antitumor $\mathrm{CD}^{+} \mathrm{T}$ cell responses. This effect might be ascribed to the reduced Treg activity due to lack of IL-35, but this possibility was not addressed (60). In contrast, impaired $\mathrm{CD}^{+} \mathrm{T}$ cell-mediated antitumor responses against subcutaneously injected B16F10 melanoma were also reported in EBI3deficient mice, suggesting a phenotype of IL-27 deficiency rather than IL-35 deficiency (54). Moreover, of note, several tumors themselves were reported to be characterized by the selective expression of EBI3 in the absence of p28, indicating a role for EBI3 independent of IL-27 and IL-35 $(61,62)$. EBI3 was demonstrated to be a prognostic factor for lung cancer, Burkitt lymphoma, and diffuse large B cell lymphoma $(63,64)$, and forced expression of EBI3 in tumors was shown to promote tumor growth in vitro (63). Therefore, intriguingly, these phenomena may not be explained by IL-27, IL-35, and probably IL-39, implying a role for EBI3 as an intracellular molecule targeting presumably growth-related molecules in the progression of tumors, as clarified here.

We have demonstrated the role of intracellular EBI3 in promoting the proper folding of target protein and augmenting its expression at the protein level by binding to calnexin and its target protein, presumably through enhancing chaperone activity (Supplemental Figure 7). Although calnexin is constitutively and ubiquitously expressed, EBI3 expression is inducible through activation of Toll-like receptor and $\mathrm{T}$ cell receptor. Therefore, the present results could open an avenue to establishing a concept of EBI3 as playing an important role in augmenting target molecule expression at the protein level in collaboration with calnexin under inflammatory conditions. These conditions are in contrast to steady-state conditions in which calnexin alone predominantly promotes the proper folding of proteins. Identification of other possible target molecules that EBI3 binds to would further generalize the paradigm of EBI3 playing an important role in augmenting target molecule expression at the protein level together with calnexin under inflammatory conditions.

\section{Methods}

Mice. WT C57BL/6 mice and RAG2-deficient mice (C57BL/6 background) were purchased from Sankyo Labo Service and Jackson Laboratory. EBI3-deficient mice (C57BL/6 background) were from Jackson Laboratory. Green mice, which are transgenic mice ubiquitously and constitutively expressing EGFP cDNA under the control of a chicken actin promoter and cytomegalovirus enhancer (30), were provided by M. Okabe (Osaka University, Osaka, Japan) and M. Ito (Tokyo Medical University). All mice were maintained under pathogen-free conditions.

Cell culture. Splenic CD4 ${ }^{+} \mathrm{T}$ cells, lamina propria mononuclear cells, and PLAT-E packaging cells (65) (provided by T. Kitamura, University of Tokyo) were cultured at $37^{\circ} \mathrm{C}$ under $5 \% \mathrm{CO}_{2} / 95 \%$ air in RPMI 1640 (MilliporeSigma) containing 10\% FBS, $50 \mu \mathrm{M}$ 2-mercaptoethanol, and $100 \mu \mathrm{g} / \mathrm{mL}$ kanamycin (Meiji Seika). Human embryonic kidney 293T (HEK293T) cells and AD293 cells (Stratagene), a derivative of HEK293 cells with improved cell adherence and plaque-formation properties, were cultured in DMEM (Invitrogen) containing 10\% FCS, $100 \mathrm{U} / \mathrm{mL}$ penicillin, and $100 \mu \mathrm{g} / \mathrm{mL}$ streptomycin (Invitrogen). The HEK293-F cell line is derived from HEK293 cells and was adapted to suspension culture in serum-free medium of FreeStyle 293 Expression Medium (Invitrogen).

Plasmid. Mouse IL-23R $\alpha, \mathrm{EBI} 3$, and calnexin cDNAs were isolated by RT-PCR using total RNA prepared from concanavalin A-activated spleen cells, confirmed by sequencing, and subcloned into p3xFLAGCMV-9 and 14 vectors (MilliporeSigma), pCXN2 (66), p3xMYCCMV14 (MilliporeSigma), and pMX-IRES-GFP (67) (provided by T. Kitamura). 3xFLAG-tagged IL-23R $\alpha$ and IL-23R $\alpha$ variant G149R (28) were generated using standard PCR methods, confirmed by sequencing, and subcloned into these vectors and pMX-IRES-GFP.

Induction and assessment of colitis. Naive $\mathrm{CD} 4^{+} \mathrm{CD} 25^{-} \mathrm{CD} 62 \mathrm{~L}^{+} \mathrm{T}$ cells were isolated and purified from spleens by using the mouse naive $\mathrm{CD}^{+} \mathrm{T}$ cell Isolation Kit together with biotin anti-CD25 (PC61), and AutoMACS Pro (all from Miltenyi Biotec). The purity of naive $\mathrm{CD} 4^{+} \mathrm{T}$ cells was routinely greater than $95 \%$. RAG2-deficient mice were injected with $2 \times 10^{5}$ naive $\mathrm{CD} 4^{+} \mathrm{T}$ cells intravenously, monitored for weight loss, and sacrificed by $\mathrm{CO}_{2}$ asphyxiation 3 to 8 weeks after initiation of the experiment. At the time of sacrifice, mouse colons were removed and flushed, and the length was measured from rectum to cecum. A $1 \mathrm{~cm}$ section of large intestine proximal to the cecum was removed, flushed with PBS, and immediately fixed in $20 \%$ buffered formalin. Tissues were embedded in paraffin and cut using standard histological techniques. Five-micrometer tissue sections were stained with H\&E. Colitis severity was scored in the proximal colon, medial colon, distal colon, and rectum on a scale of 0 to 5 , with 0 and 5 representing a normal colon and severe colitis, respectively. The scores of 4 anatomical regions were totaled for each mouse to yield a total histological score.

Isolation of lamina propria mononuclear cells. Colons were mechanically dissected into small pieces, and intestinal epithelial cells were removed by incubation in ethylenediaminetetraacetic acid. Remaining tissue was digested using collagenase D and DNase I (Roche Diagnostics). Digested tissue was passed through a $40 \mu \mathrm{m}$ cell strainer, and the remaining cellular content was separated from debris using a $40 \% / 75 \%$ Percoll gradient.

Th differentiation assay. Naive $\mathrm{CD} 4^{+} \mathrm{T}$ cells $\left(5 \times 10^{5}\right.$ cells $\left./ \mathrm{mL}\right)$ were stimulated with plate-bound anti-CD3 (145-2C11, ATCC, $2 \mu \mathrm{g} / \mathrm{mL})$ and anti-CD28 (37.51, BD Biosciences, $0.5 \mu \mathrm{g} / \mathrm{mL}$ ) or soluble anti-CD3 $(1 \mu \mathrm{g} / \mathrm{mL})$ and irradiated spleen cells depleted of $\mathrm{T}$ and NK cells (as antigen-presenting cells, $4 \times 10^{4}$ cells $/ \mathrm{mL}$ ) under Th1 polarizing conditions with IL-12 (PeproTech, $10 \mathrm{ng} / \mathrm{mL}$ ) and anti-IL-4 (11B11, ATCC), nonpathogenic Th17 polarizing conditions with TGF- $\beta 1$ (PeproTech, 5 $\mathrm{ng} / \mathrm{mL})$, hyper-IL-6 (68) (10 ng/mL, generated in house), anti-IL-4, and anti-IFN- $\gamma$ (XMG1.2, Bio X Cell), and pathogenic Th17 polarizing conditions with IL-1 $\beta$ (R\&D Systems, $10 \mathrm{ng} / \mathrm{mL}$ ), hyper-IL-6 (10 ng/ 
mL), IL-23 (R\&D Systems, $10 \mathrm{ng} / \mathrm{mL}$ ), anti-IL-4, and anti-IFN- $\gamma$. All anti-cytokine neutralizing monoclonal antibodies were used at $10 \mu \mathrm{g} /$ $\mathrm{mL}$. Spleen cells depleted of $\mathrm{T}$ and NK cells were negatively purified with anti-CD90.1 (Thy1.1) and anti-CD49b (DX5) magnetic beads and AutoMACS Pro (all from Miltenyi Biotec). On day 3, cells were expanded in complete medium containing human IL-2 (Shionogi \& Co., 50 $\mathrm{U} / \mathrm{mL}$ ). On day 5 , cells were collected, washed, and restimulated with PMA and ionomycin in the presence of brefeldin A; this was followed by intracellular cytokine staining as described below. Cells were also restimulated at $5 \times 10^{5}$ cell $/ \mathrm{mL}$ with plate-bound anti-CD3 $(2 \mu \mathrm{g} / \mathrm{mL})$. After 24 hours, culture supernatants were harvested and assayed for cytokine production by ELISA. To see the effects of soluble EBI3, recombinant EBI3 (Novus Biologicals) was added onto naive $\mathrm{CD} 4^{+} \mathrm{T}$ cells stimulated under pathogenic Th17 polarizing conditions.

Flow cytometry. Single-cell suspensions were obtained from spleens and lamina propria mononuclear cells. For intracellular cytokine staining, single-cell suspensions from lamina propria mononuclear cells were restimulated for 4 hours with $50 \mathrm{ng} / \mathrm{mL}$ PMA (MilliporeSigma) and $500 \mathrm{ng} / \mathrm{mL}$ ionomycin (MilliporeSigma) in the presence of $5 \mu \mathrm{g} / \mathrm{mL}$ brefeldin A (eBioscience). Cells were then stained with PE-Cy7-conjugated anti-CD4 (GK1.5, BioLegend), fixed with Fixation Buffer (eBioscience) for 30 minutes, and permeabilized with Permeabilization Buffer (eBioscience) for 30 minutes. Then, samples were stained intracellularly with PE-conjugated anti-IL-17 (TC1118H10, BD Biosciences) or allophycocyanin-conjugated (APC-conjugated) anti-IL-17 (TC11-18H10.1, BioLegend) and PE-conjugated antiIL-10 (JES5-16E3, eBioscience), PerCP-Cy5.5-conjugated anti-IFN- $\gamma$ (XMG1.2, eBioscience), or PE-Cy7-conjugated anti-IFN- $\gamma$ (XMG1.2, BioLegend). For cell-surface staining of IL-23R $\alpha$ and IL-12R $\beta 1$, cells were stained with APC-conjugated anti-IL-23R $\alpha$ (12B2B64, BioLegend), PE-conjugated anti-IL-12R $\beta 1$ (R\&D Systems), and FITC-conjugated anti-CD4 (GK1.5, BioLegend). Stained cells were then analyzed on a FACSCanto II Flow Cytometer (BD Biosciences), followed by analysis with FACSDiva Software (BD Biosciences) or FlowJo software (Tree Star). For cell-surface staining, 7-amino actinomycin D (7-ADD) staining was used to exclude dead or damaged cells from analysis.

For intracellular and cell-surface staining of IL-23R $\alpha$, naive CD $4^{+}$ $\mathrm{T}$ cells were stimulated with plate-bound anti-CD3 $(2 \mu \mathrm{g} / \mathrm{mL})$ and anti-CD28 $(1 \mu \mathrm{g} / \mathrm{mL})$ under pathogenic Th17 polarization with IL-1 $\beta$ (10 ng/mL), hyper-IL-6 (100 ng/mL), IL-23 (100 ng/mL), anti-IL-4, and anti-IFN- $\gamma$ for 3 days and expanded with IL-2. On day 5 , cells were stained with anti-IL-23R $\alpha$ (antigen affinity-purified polyclonal goat IgG, R\&D Systems) on the cell surface or stained intracellularly with anti-IL-23R $\alpha$ (R\&D Systems) after fixation and permeabilization, then further stained with donkey anti-goat IgG conjugated with biotin (Jackson ImmunoResearch) followed by streptavidin-APC (BioLegend). Normal goat IgG (MilliporeSigma) was used as a control antibody. The anti-IL-23R $\alpha$ (R\&D Systems) showed less nonspecific binding for intracellular staining of IL-23R $\alpha$ than did the anti-IL-23R $\alpha$ antibody (12B2B64, BioLegend) (data not shown).

AD293 cells were transiently transfected by using FuGENE 6 (Promega) with pMX-IRES-GFP-3xFLAG-tagged IL-23R $\alpha$ or its G149R variant and pCXN2-EBI3. The total amount of DNA was adjusted to be kept equal with the empty vector. After 72 hours, cells were fixed with IC Fixation Buffer (eBioscience), and intracellularly stained for FLAGIL-23R $\alpha$ using anti-FLAG rabbit antibody (clone 1042E, R\&D Systems) followed by donkey antibody against rabbit IgG conjugated with Alexa
Fluor 647 (Abcam) and EBI3 using anti-EBI3 rat antibody (clone 360-1, generated in house) followed by goat antibody against rabbit IgG conjugated with PE (Jackson ImmunorResearch, catalog 112-116-071). For analysis of cell-surface expression of FLAG-IL-23R $\alpha$, cells were first stained for FLAG-IL-23R $\alpha$ using anti-FLAG rabbit antibody (clone $1042 \mathrm{E}$ ) without fixation, followed by biotin goat antibody against rabbit IgG conjugated with biotin (Vector Laboratories, catalog BA-1000), and streptavidin-APC (BioLegend, catalog 405207). Then cells were intracellularly stained for EBI3 as described above.

Western blotting. Naive $\mathrm{CD} 4^{+} \mathrm{T}$ cells were stimulated with platebound anti-CD3 and anti-CD28 under pathogenic Th17 polarization conditions with IL-1 $\beta$ (10 ng/mL), hyper-IL-6 (50 ng/mL), IL-23 (50 $\mathrm{ng} / \mathrm{mL}$ ), anti-IL-4, and anti-IFN- $\gamma$ for 3 days and expanded with IL-2 for more 3 days. Stimulated cells were also treated with cycloheximide (MilliporeSigma), the proteasome inhibitor MG132 (Merck Millipore), or the lysosomal protease inhibitors pepstatin A (MilliporeSigma) and E64d (MilliporeSigma). Cells were then lysed at the indicated time points in a lysis buffer containing protease inhibitors, and the resultant cell lysates were separated by SDS-PAGE under reducing conditions and transferred to a polyvinylidene difluoride membrane (Merck Millipore). The membrane was blocked, probed with antibodies against EBI3 (Santa Cruz Biotechnology Inc., catalog sc-32869), p28 (R\&D Systems, catalog AF1834), (R\&D Systems, clone\#27537, catalog MAB1570), IL-23R $\alpha$ (R\&D Systems, catalog AF1686), IL-12R $\beta 1$ (Santa Cruz Biotechnology Inc., catalog sc-658), c-Maf (Santa Cruz Biotechnology Inc., catalog sc-7866), SOCS3 (Santa Cruz Biotechnology Inc., catalog sc-9023), and actin (MilliporeSigma), followed by an appropriate secondary antibody conjugated to horseradish peroxidase, and visualized with the enhanced chemiluminescence detection system (GE Healthcare) according to the manufacturer's instructions. Immunoreactive bands were detected with a ChemiDoc XRS (Bio-Rad), and the intensity of each band was quantified with the Image Lab (Bio-Rad) or Image (NIH) program.

HEK293T or 293-F cells were transiently transfected by using FuGENE 6 with p3xFLAG-CMV-14-IL-23R $\alpha$, pME18S-IL-12R $\beta 1-H A$ (69), and pCXN2-EBI3. The total amount of DNA was adjusted to be kept equal with the empty vector. After 72 hours, total cell lysates were prepared and subjected to Western blotting using antibodies against FLAG (M2, MilliporeSigma), HA (6E2, Cell Signaling), EBI3 (Santa Cruz Biotechnology Inc., catalog sc-32869), calnexin (Santa Cruz Biotechnology Inc., catalog sc-6465), STAT3 (Santa Cruz Biotechnology Inc., catalog sc-482), pY-STAT3 (Cell Signaling BioTechnology Inc., catalog 9131s), T-bet (4B10, Santa Cruz Biotechnology Inc.), and actin (MilliporeSigma, catalog A2066). To detect phosphorylation of STAT3, transfected cells were serum starved overnight, then stimulated by IL-23 (10 ng/mL) for varied times and subjected to Western blotting.

ELISA. Amounts of IFN- $\gamma$, TNF- $\alpha$, GM-CSF, IL-6, IL-17, and IL-22 in culture supernatants were determined by ELISA according to the manufacturers' instructions (R\&D Systems or BD Biosciences). Amounts of soluble EBI3 were determined by ELISA (Aviva Systems Biology).

Retroviral infection. Retroviral vectors were transfected into PLAT-E packaging cells using FuGENE 6, and supernatants of these cells cultured for 3 days were used as the source of viral particles. Naive $\mathrm{CD} 4^{+}$ $\mathrm{T}$ cells were stimulated with plate-coated anti-CD3 and soluble antiCD28 for 24 hours and transduced with viral particles by spin infection $(780 \mathrm{~g}), 90$ minutes, $25^{\circ} \mathrm{C}$ ) using $10 \mu \mathrm{g} / \mathrm{mL}$ polybrene. Resultant cells were further cultured under pathogenic Th17 polarizing conditions for 3 days and then analyzed for intracellular expression of IFN- $\gamma$. 
Immunoprecipitation. Cells were lysed in $1 \%$ Nonidet $\mathrm{P}-40$ lysis buffer (10 mM Tris-HCl, pH 7.5, $150 \mathrm{mM} \mathrm{NaCl}, 1 \mathrm{mM}$ EDTA) supplemented with protease inhibitor cocktail followed by centrifugation. The cell lysate was incubated with antibody $(1 \mu \mathrm{g})$ conjugated to protein $\mathrm{G}^{-}$Sepharose (Amersham Pharmacia Biotech.) for 2 hours to overnight at $4^{\circ} \mathrm{C}$. After the beads were washed, the complexes were separated on an SDS-PAGE under reducing conditions and subjected to Western blotting. In the case of HEK293T cells transfected with respective expression vectors, antiFLAG (M2), anti-EBI3 (Santa Cruz Biotechnology Inc.), and anti-calnexin (Santa Cruz Biotechnology Inc.) were used. In the case of CD4 ${ }^{+} \mathrm{T}$ cells, cell lysates were immunoprecipitated with anti-EBI3 (360-1) followed by Western blotting with anti-IL-23R $\alpha$ (R\&D Systems), or immunoprecipitated with anti-EBI3 (Santa Cruz Biotechnology Inc.) followed by Western blotting with anti-calnexin (Santa Cruz Biotechnology Inc.).

Statistics. Statistical analyses were performed by using unpaired, 2-tailed Student's $t$ test for comparisons of 2 groups and 1-way ANOVA with the Dunnett's and Tukey's multiple comparison test for comparing more than 3 groups using GraphPad Prism 7 (GraphPad Software Inc.). P $<0.05$ was considered as indicating a statistically significant difference.

Study approval. All animal studies were approved by the president and the IACUC of Tokyo Medical University and performed in accordance with institutional, science community, and national guidelines for animal experimentation.

Other methods are described in the Supplemental Methods.

\section{Author contributions}

TY directed the study. IM and TY designed experiments. IM, MO, $\mathrm{HH}, \mathrm{YC}, \mathrm{NO}, \mathrm{SI}$, and CK performed experiments and analyzed results. $\mathrm{MX}, \mathrm{KS}, \mathrm{KF}, \mathrm{MK}, \mathrm{SH}$, and $\mathrm{KM}$ provided technical support and discussed results. IM and TY wrote the manuscript.

\section{Acknowledgments}

The authors thank M. Okabe (Osaka University) and M. Ito (Tokyo Medical University), G. Trinchieri (NIH) and H. Nariuchi (University of Tokyo), T. Kitamura (University of Tokyo), R. Pine, and J.J. O'Shea (NIH), and the Animal Research Center of Tokyo Medical University for green mice, C17.8 hybridoma, PLAT-E and pMXIRES-GFP, p3xGAS-Luc reporter construct, and animal care. The authors also thank K. Kaneko, K. Mitobe, R. Tsunoda, and J. Furusawa, who previously belonged to our laboratory. This study was supported in part by Grants-in-Aid for Scientific Research and by the program for the Strategic Research Foundation at Private Universities from the Ministry of Education, Culture, Sports, Science and Technology, Japan.

Address correspondence to: Takayuki Yoshimoto, Department of Immunoregulation, Institute of Medical Science, Tokyo Medical University, 6-1-1 Shinjuku, Shinjuku-ku, Tokyo 160-8402, Japan. Phone: 81.3.3351.6141; Email: yoshimot@tokyo-med.ac.jp.
1. Tait Wojno ED, Hunter CA, Stumhofer JS. The immunobiology of the interleukin-12 family: room for discovery. Immunity. 2019;50(4):851-870.

2. Devergne O, et al. A novel interleukin-12 p40-related protein induced by latent EpsteinBarr virus infection in B lymphocytes. J Virol. 1996;70(2):1143-1153.

3. Pflanz S, et al. IL-27, a heterodimeric cytokine composed of EBI3 and $\mathrm{p} 28$ protein, induces proliferation of naive CD4+ T cells. Immunity. 2002;16(6):779-790.

4. Collison LW, et al. The inhibitory cytokine IL-35 contributes to regulatory T-cell function. Nature. 2007;450(7169):566-569.

5. Wang X, et al. A novel IL-23p19/Ebi3 (IL-39) cytokine mediates inflammation in Lupus-like mice. Eur J Immunol. 2016;46(6):1343-1350.

6. Kastelein RA, Hunter CA, Cua DJ. Discovery and biology of IL-23 and IL-27: related but functionally distinct regulators of inflammation. Annu Rev Immunol. 2007;25:221-242.

7. Hall AO, Silver JS, Hunter CA. The immunobiology of IL-27. Adv Immunol. 2012;115:1-44.

8. Collison LW, Vignali DA. Interleukin-35: odd one out or part of the family? Immunol Rev. 2008;226:248-262.

9. Wang X, et al. Interleukin (IL)-39 [IL-23p19/ Epstein-Barr virus-induced 3 (Ebi3)] induces differentiation/expansion of neutrophils in lupus-prone mice. Clin Exp Immunol. 2016;186(2):144-156.

10. Xavier RJ, Podolsky DK. Unravelling the pathogenesis of inflammatory bowel disease. Nature. 2007;448(7152):427-434.

11. Maloy KJ, Powrie F. Intestinal homeostasis and its breakdown in inflammatory bowel disease. Nature. 2011;474(7351):298-306.

12. Yen D, et al. IL-23 is essential for T cell-mediated colitis and promotes inflammation via IL-17 and IL-6. J Clin Invest. 2006;116(5):1310-1316.

13. Uhlig HH, et al. Differential activity of IL-12 and IL-23 in mucosal and systemic innate immune pathology. Immunity. 2006;25(2):309-318.

14. Hue S, et al. Interleukin-23 drives innate and T cell-mediated intestinal inflammation. JExp Med. 2006;203(11):2473-2483.

15. Kullberg MC, et al. IL-23 plays a key role in Helicobacter hepaticus-induced $\mathrm{T}$ cell-dependent colitis. JExp Med. 2006;203(11):2485-2494.

16. Elson CO, et al. Monoclonal anti-interleukin 23 reverses active colitis in a T cell-mediated model in mice. Gastroenterology. 2007;132(7):2359-2370.

17. McGeachy MJ, et al. TGF-beta and IL-6 drive the production of IL-17 and IL-10 by T cells and restrain $\mathrm{T}(\mathrm{H})-17$ cell-mediated pathology. Nat Immunol. 2007;8(12):1390-1397.

18. Lee YK, et al. Late developmental plasticity in the T helper 17 lineage. Immunity. 2009;30 (1):92-107.

19. Hirota K, et al. Fate mapping of IL-17-producing $\mathrm{T}$ cells in inflammatory responses. Nat Immunol. 2011;12(3):255-263.

20. Morrison PJ, et al. Th17-cell plasticity in Helicobacter hepaticus-induced intestinal inflammation. Mucosal Immunol. 2013;6(6):1143-1156.

21. Morrison PJ, Ballantyne SJ, Kullberg MC. Interleukin-23 and Thelper 17-type responses in intestinal inflammation: from cytokines to T-cell plasticity. Immunology. 2011;133(4):397-408.

22. Muranski P, Restifo NP. Essentials of Th17 cell commitment and plasticity. Blood. 2013;121(13):2402-2414.

23. Duerr RH, et al. A genome-wide association study identifies IL23R as an inflammatory bowel disease gene. Science. 2006;314(5804):1461-1463.

24. Wellcome Trust Case Control Consortium.
Genome-wide association study of 14,000 cases of seven common diseases and 3,000 shared controls. Nature. 2007;447(7145):661-678.

25. Helenius A, Aebi M. Roles of N-linked glycans in the endoplasmic reticulum. Annu Rev Biochem. 2004;73:1019-1049.

26. Parodi AJ. Protein glucosylation and its role in protein folding. Annu Rev Biochem. 2000;69:69-93.

27. Caramelo JJ, Parodi AJ. Getting in and out from calnexin/calreticulin cycles. J Biol Chem. 2008;283(16):10221-10225.

28. Sivanesan D, et al. IL23R (interleukin 23 receptor) variants protective against inflammatory bowel diseases (IBD) display loss of function due to impaired protein stability and intracellular trafficking. J Biol Chem. 2016;291(16):8673-8685.

29. Stumhofer JS, et al. A role for IL-27p28 as an antagonist of gp130-mediated signaling. Nat Immunol. 2010;11(12):1119-1126.

30. Okabe M, Ikawa M, Kominami K, Nakanishi T, Nishimune Y. 'Green mice' as a source of ubiquitous green cells. FEBS Lett. 1997;407(3):313-319.

31. Ma N, et al. Ebi3 promotes T- and B-cell division and differentiation via STAT3. Mol Immunol. 2019;107:61-70.

32. Parham C, et al. A receptor for the heterodimeric cytokine IL-23 is composed of IL-12Rbeta1 and a novel cytokine receptor subunit, IL-23R. J Immunol. 2002;168(11):5699-5708.

33. Ciechanover A. Intracellular protein degradation: from a vague idea through the lysosome and the ubiquitin-proteasome system and onto human diseases and drug targeting. Rambam Maimonides Med J. 2012;3(1):e0001.

34. Mizushima N, Komatsu M. Autophagy: renovation of cells and tissues. Cell. 2011;147(4):728-741.

35. Brodsky JL. Cleaning up: ER-associated degrada- 
tion to the rescue. Cell.2012;151(6):1163-1167.

36. Schagger $\mathrm{H}$, von Jagow $\mathrm{G}$. Blue native electrophoresis for isolation of membrane protein complexes in enzymatically active form. Anal Biochem. 1991;199(2):223-231.

37. Pine R, Canova A, Schindler C. Tyrosine phosphorylated p91 binds to a single element in the ISGF2/ IRF-1 promoter to mediate induction by IFN alpha and IFN gamma, and is likely to autoregulate the p91 gene. ЕМBО J.1994;13(1):158-167.

38. Ran FA, et al. Genome engineering using the CRISPR-Cas9 system. Nat Protoc. 2013;8(11):2281-2308

39. Germann T, Rude E, Mattner F, Gately MK. The IL-12 p40 homodimer as a specific antagonist of the IL-12 heterodimer. Immunol Today. 1995;16(10):500-501.

40. Gillessen S, et al. Mouse interleukin-12 (IL-12) p40 homodimer: a potent IL-12 antagonist. Eur J Immunol. 1995;25(1):200-206.

41. Zhao J, et al. F-box protein FBXL19-mediated ubiquitination and degradation of the receptor for IL-33 limits pulmonary inflammation. Nat Immunol. 2012;13(7):651-658.

42. Wirtz S, et al. EBV-induced gene 3 transcription is induced by TLR signaling in primary dendritic cells via NF-kappa B activation. J Immunol. 2005;174(5):2814-2824.

43. Sato K, et al. Marked induction of c-Maf protein during Th17 cell differentiation and its implication in memory Th cell development. J Biol Chem. 2011;286(17):14963-14971.

44. Starr R, et al. A family of cytokineinducible inhibitors of signalling. Nature. 1997;387(6636):917-921.

45. Yamamoto-Furusho JK, Posadas-Sanchez R, Alvarez-Leon E, Vargas-Alarcon G. Protective role of Interleukin 27 (IL-27) gene polymorphisms in patients with ulcerative colitis. Immunol Lett. 2016;172:79-83.

46. Gehlert T, Devergne O, Niedobitek G. EpsteinBarr virus (EBV) infection and expression of the interleukin-12 family member EBV-induced gene 3 (EBI3) in chronic inflammatory bowel disease. JMed Virol. 2004;73(3):432-438.

47. Omata F, Birkenbach M, Matsuzaki S, Christ AD,
Blumberg RS. The expression of IL-12 p40 and its homologue, Epstein-Barr virus-induced gene 3 , in inflammatory bowel disease. Inflamm Bowel Dis. 2001;7(3):215-220.

48. Christ AD, et al. An interleukin 12-related cytokine is up-regulated in ulcerative colitis but not in Crohn's disease. Gastroenterology. 1998;115(2):307-313.

49. Nieuwenhuis EE, et al. Disruption of T helper 2-immune responses in Epstein-Barr virusinduced gene 3-deficient mice. Proc Natl Acad Sci U S A. 2002;99(26):16951-16956.

50. Hasegawa H, et al. Expanding diversity in molecular structures and functions of the IL-6/IL-12 heterodimeric cytokine family. Front Immunol. 2016;7:479.

51. Turnis ME, et al. Interleukin-35 limits anti-tumor immunity. Immunity. 2016;44(2):316-329.

52. Liu JQ, et al. Increased Th17 and regulatory $\mathrm{T}$ cell responses in EBV-induced gene 3-deficient mice lead to marginally enhanced development of autoimmune encephalomyelitis. J Immunol. 2012;188(7):3099-3106.

53. Wirtz S, Billmeier U, McHedlidze T, Blumberg RS, Neurath MF. Interleukin- 35 mediates mucosal immune responses that protect against T-cell-dependent colitis. Gastroenterology. 2011;141(5):1875-1886.

54. Liu Z, et al. Epstein-Barr virus-induced gene 3-deficiency leads to impaired antitumor T-cell responses and accelerated tumor growth. Oncoimmunology. 2015;4(7):e989137.

55. Dokmeci E, et al. EBI3 deficiency leads to diminished $\mathrm{T}$ helper type 1 and increased $\mathrm{T}$ helper type 2 mediated airway inflammation. Immunology. 2011;132(4):559-566.

56. Siebler J, et al. Cutting edge: a key pathogenic role of IL-27 in T cell- mediated hepatitis. J Immunol. 2008;180(1):30-33.

57. Zahn S, et al. Impaired Th1 responses in mice deficient in Epstein-Barr virus-induced gene 3 and challenged with physiological doses of Leishmania major. Eur J Immunol. 2005;35(4):1106-1112.

58. Kimura D, et al. Interleukin-27-producing CD4(+) T cells regulate protective immunity during malaria parasite infection. Immunity.
2016;44(3):672-682.

59. Deng JH, et al. Accumulation of EBI3 induced by virulent Mycobacterium tuberculosis inhibits apoptosis in murine macrophages. Pathog Dis. 2019;77(1):ftz007.

60. Sauer KA, et al. Immunosurveillance of lung melanoma metastasis in EBI-3-deficient mice mediated by CD8+ T cells. J Immunol. 2008;181(9):6148-6157.

61. Larousserie F, et al. Analysis of interleukin-27 (EBI3/p28) expression in Epstein-Barr virus- and human T-cell leukemia virus type 1-associated lymphomas: heterogeneous expression of EBI3 subunit by tumoral cells. Am J Pathol. 2005;166(4):1217-1228.

62. Larousserie F, et al. Variable expression of Epstein-Barr virus-induced gene 3 during normal B-cell differentiation and among B-cell lymphomas. J Pathol. 2006;209(3):360-368.

63. Nishino R, et al. Identification of Epstein-Barr virus-induced gene 3 as a novel serum and tissue biomarker and a therapeutic target for lung cancer. Clin Cancer Res. 2011;17(19):6272-6286.

64. Gonin J, et al. Epstein-Barr virus-induced gene 3 (EBI3): a novel diagnosis marker in Burkitt lymphoma and diffuse large B-cell lymphoma. PLoS One. 2011;6(9):e24617.

65. Morita S, Kojima T, Kitamura T. Plat-E: an efficient and stable system for transient packaging of retroviruses. Gene Ther. 2000;7(12):1063-1066.

66. Niwa H, Yamamura K, Miyazaki J. Efficient selection for high-expression transfectants with a novel eukaryotic vector. Gene. 1991;108(2):193-199.

67. Kitamura T, et al. Retrovirus-mediated gene transfer and expression cloning: powerful tools in functional genomics. Exp Hematol. 2003;31(11):1007-1014.

68. Owaki T, et al. STAT3 is indispensable to IL-27-mediated cell proliferation but not to IL-27-induced Th1 differentiation and suppression of proinflammatory cytokine production. J Immunol. 2008;180(5):2903-2911.

69. Yoshimoto T, et al. Positive modulation of IL-12 signaling by sphingosine kinase 2 associating with the IL-12 receptor beta 1 cytoplasmic region. J Immunol. 2003;171(3):1352-1359. 